\title{
DOES THE MARKET REWARD QUALITY?: EVIDENCE FROM INDIA
}

\author{
Zachary Wagner \\ Somalee Banerjee \\ Manoj Mohanan \\ Neeraj Sood \\ Working Paper 26460 \\ http://www.nber.org/papers/w26460 \\ NATIONAL BUREAU OF ECONOMIC RESEARCH \\ 1050 Massachusetts Avenue \\ Cambridge, MA 02138 \\ November 2019
}

We would like to thank Rebecca Dizon-Ross, Jishnu Das, and participants at ASHEcon 2019 for helpful comments. We would also like to thank Sneha Nimmagadda for excellent field work management. The views expressed herein are those of the authors and do not necessarily reflect the views of the National Bureau of Economic Research.

At least one co-author has disclosed a financial relationship of potential relevance for this research. Further information is available online at http://www.nber.org/papers/w26460.ack

NBER working papers are circulated for discussion and comment purposes. They have not been peer-reviewed or been subject to the review by the NBER Board of Directors that accompanies official NBER publications.

(C) 2019 by Zachary Wagner, Somalee Banerjee, Manoj Mohanan, and Neeraj Sood. All rights reserved. Short sections of text, not to exceed two paragraphs, may be quoted without explicit permission provided that full credit, including $\odot$ notice, is given to the source. 
Does The Market Reward Quality?: Evidence from India

Zachary Wagner, Somalee Banerjee, Manoj Mohanan, and Neeraj Sood

NBER Working Paper No. 26460

November 2019

JEL No. D12,D22,D52,I1,I11,I12

\begin{abstract}
There are two salient facts about health care in low and middle-income countries; 1) the private sector plays an important role and 2) the care provided is often of poor quality. Despite these facts we know little about what drives quality of care in the private sector and why patients continue to seek care from poor quality providers. We use two field studies in India that provide unique insight into this issue. First, we use a discrete choice experiment to show that patients are willing to pay higher prices for better technical quality (defined by correct treatment and correct diagnosis). Second, we use standardized patients to show that private providers who provide better technical quality are not able to charge higher prices. Instead providers are able to charge higher prices for elements of quality that the patient can observe (good patient interactions and more effort), which are less important for health outcomes. Taken together, this research highlights a market inefficiency and suggests that engaging patients with accessible information on technical quality of the providers in their community could shift demand to providers that provide better care and thus improve health outcomes.

Zachary Wagner

RAND Corporation

1776 Main Street

Santa Monica, CA 90401

zwagner@rand.org

Somalee Banerjee

Neerman Research

H-38 Jangpura Extension

New Delhi, N/A 110014

India

somalee.banerjee@neerman.org

Manoj Mohanan

Sanford School of Public Policy

201 Science Drive RH128

Durham, NC 27708

manoj.mohanan@duke.edu

Neeraj Sood

Schaeffer Center for Health Policy and Economics

3335 S. Figueroa Street, Unit A

Los Angeles, CA 90089-7273

and NBER

nsood@healthpolicy.usc.edu
\end{abstract}




\section{Introduction}

There are two salient facts about health care in low and middle-income countries. First, the private sector plays an important role in the provision of health care for common health conditions (Grépin, 2016). Second, health care provided by private as well as public providers is often of poor quality (Banerjee et al., 2004, Basu et al., 2012, Berendes et al., 2011, Das et al., 2018, Mohanan et al., 2015, Sood and Wagner, 2014, Wagner et al., 2014a, Wagner et al., 2014b). For example, in India, the location of this study, over $75 \%$ of caretakers of children with diarrhea sought care in the for-profit private sector. However, only $54 \%$ of these children received ORS, a cheap but effective and universally recommended treatment for preventing dehydration and mortality from diarrhea. Twenty percent of these children receive antibiotics which are unnecessary for uncomplicated diarrhea (DHS, 2016). These salient facts imply that thousands of deaths could be prevented and expense on unnecessary treatment spared if we could improve quality of care (Alkire et al., 2018, Das et al., 2014).

Despite these facts, we know little about what drives quality of care and why patients continue to seek care from health providers who provide poor quality care. Recent reports from the Lancet Global Health, the National Academies, and the World Health Organization highlight the urgent need for global quality improvements (Kruk et al., 2018, National Academies of Sciences and Medicine, 2019, World Health Organization, 2018). One important question that we address in this paper is whether there is a business case for quality. That is, can high quality providers charge higher fees or attract more patients than poor quality providers.

Quality of health care includes several elements including safety, effectiveness, personcenteredness, access, efficiency, and equity (National Academies of Sciences and Medicine, 2019). In this paper, we focus primarily on safety and effectiveness, which we refer to as technical quality, and patient centeredness, which we refer to as observable quality (observable to the patient). We distinguish between these two elements of quality because we expect the market to reward them differently. To the best of our knowledge, we know of only one peer reviewed study that examined the association between provider fees and quality of care. Although it found that technical quality (providing correct treatment) was positively associated with higher provider fees in bivariate analysis, these associations reduced in magnitude and became statistically insignificant 
when controlling for confounding factors (Das et al., 2016b). Moreover, correct diagnosis was not correlated with prices. The same study found that providers who spent more time with patients investigating symptoms and case history (observable quality) were able to charge higher prices even when adjusting for confounding factors.

One possible explanation for why there is no business case for correct treatment and diagnosis is that patients might not place much weight on technical quality of care when choosing providers. Perhaps price, convenience of the clinic, and providers' attention and empathy to the patient primarily drive provider choices. Past research does indeed show that price and distance are important determinants of health service utilization in low-income countries (Dupas and Miguel, 2017, Kremer and Glennerster, 2011, Lagarde and Palmer, 2008, Wagner et al., 2019) and that providers' attention and empathy to the patient is important for patient satisfaction and provider choice (Andaleeb et al., 2007, Kim et al., 2004, Kitapci et al., 2014, Murti et al., 2013, Srivastava et al., 2015, Zanolini et al., 2018). Another potential explanation is that patients value technical quality more than other provider attributes but do not have the knowledge or tools to distinguish between care that is safe and effective versus care that is ineffective or harmful. However, little is known about whether patients value technical quality in primary care settings more than other provider attributes or whether they can discern the difference between good versus poor technical quality care. Understanding both patient demand for technical quality and the business case for technical quality is fundamental for designing public policy for improving the quality of care in the private sector. For example, if people prefer better technical quality, but the market does not reward technical quality, this would suggest a market inefficiency that could be corrected by engaging patients and providing them with tools to discern the quality of care provided by different providers in their community.

In this study, we examine these issues using two field experiments in Bihar, India focused on care for childhood diarrhea and pneumonia. In the first analysis we used a discrete choice experiment (DCE), where we asked parents of children to choose between two providers with different characteristics (price, technical quality, distance, and medical training), to which to take their child for care for a hypothetical episode of uncomplicated diarrhea. This allows us to examine the preferences of people seeking care, and which attributes are most influential for choosing a 
provider. In the second analysis, we used data from standardized patients (SPs) who posed as parents of children with diarrhea or pneumonia to measure quality and examine the association between different dimensions of quality and provider fees. The combination of these two data sources allows us to examine 1) the extent to which people value technical quality and would be willing to pay higher prices for better quality, and 2) whether the market rewards technical quality with the ability to charge higher prices.

Our DCE results show that patients had a strong preference for technical quality and that people were willing to pay substantially more and travel much further for better quality providers. Switching from the lowest quality level (one star) to the highest quality level (five stars) increased the probability of choosing a provider by 64 percentage points. In contrast, reducing the price per visit from INR 300 (USD \$4.3) to INR 100 (USD 1.43) increased the probability of a choosing a provider by 9 percentage points. Similarly, reducing travel time to provider from 60 minutes to 10 minutes increase the probability of choosing a provider by only 4 percentage points. Provider education, a signal of provider quality, also had a large impact on the probability of choosing a provider. In particular, increasing the education from no degree to MD/MBBS increased the probability of choosing a provider by 79 percentage points.

Although the demand for technical quality is clear and substantial, providers who gave better technical care to SPs were not able to charge higher prices. We found no association between prices and correctly diagnosing illness or providing correct treatment. We do, however, find positive associations between prices and elements of quality that people can observe (asking more questions, longer visits, and better patient interactions), which are less important for improving health outcomes. We also show that, while observable quality is correlated with technical quality, a large majority of providers with good observable quality provided incorrect treatment and diagnosis. This suggests that choosing providers based on observable quality is insufficient, and will often lead to poor technical quality care.

This paper makes several important contributions to the literature on several topics. First, we contribute to the literature on provider choice. Several papers have examined the role of price on provider choice in the United States (Robinson et al., 2016, Sood et al., 2013, Whaley et al., 2014, Zhang et al., 2018) but less is known about the role of quality on provider choice. Moreover, very 
little is known about what contributes to provider choice in LMICs (Hanson et al., 2005). We show that provider choice in India is strongly driven by perceptions of quality rather than price or convenience.

Second, this paper contributes to very limited evidence on whether the market rewards good quality of care. Information asymmetries and inefficiencies in health care markets have been discussed for nearly 60 years (Arrow, 1963), but only one study we are aware of shows how these issues affect how the market rewards health care quality (Das, et al., 2016b). We find that, in spite of strong demand for good technical quality, there is no price premium to providers who provide good technical quality. Combined with previous work documenting that most providers know what good technical quality looks like (Mohanan, et al., 2015), this result suggests that asymmetric information could be the driving force of this market inefficiency. While patients want to go to the best quality providers, they are not able to correctly distinguish the good quality providers from the bad quality providers. This could be corrected by interventions to improve quality transparency.

Finally, our results contribute to the literature on quality of care in LMICs. While poor quality is widely documented (Banerjee, et al., 2004, Das et al., 2008), there is an incomplete understanding of why quality of care has failed to adequately improve. We show that the market does not reward the most essential elements of health care quality (correct treatment and diagnosis), which could contribute to persistent poor quality of care in LMICs.

The rest of the paper proceeds as follows. Section 2 describes the DCE experiment and presents results on what attributes affect provider choice, Section 3 describes the SP analysis and presents results on whether the market rewards better quality providers, section 4 presents a series of robustness tests, and section 5 discusses policy implications and concludes. 


\section{Discrete Choice Experiment}

\section{Overview}

We enrolled 500 parents in Bihar, India to participate in a DCE. The DCE was conducted in Patna, the largest city in the state of Bihar (population of 2 million). Eligible respondents were over 18years-old and were the primary caretaker for at least one child under 10-years-old (see Appendix C for more details on sampling design). Respondents were asked to imagine that their youngest child had been having diarrhea for the last 2 days. On each of these days the child had 6 watery stools, fevers, and is now very weak and not eating or drinking very well. They were informed that they would be asked to choose between two different providers from whom to seek care for their child. Each respondent was shown profiles of two different providers, which portrayed the provider's fee $(0,100,200$, or 300 rupees or USD \$1.42, \$2.84, \$4.26), medical training (MBBS/MD, ayurvedic, homeopathic, or no degree), government rating of technical quality (5 stars, 3 stars, or 1 star; explained more below) and the time to arrive at the facility (10 mins, 20 mins, 30 mins, or 60 mins)(See Table 1 for full attribute list). Attribute levels were derived using secondary data (price) and consultation with experts (time and degree). Each choice-set had two providers with a different combination of attribute levels. Respondents were told to assume that all providers have a 30-minute wait, are in an air-conditioned facility, and are in a central location, and to assume that all other characteristics between providers are the same. Each respondent was presented with a total of eight choice-sets.

\section{DCE Design}

We designed our DCE to examine the causal impact of four attributes on provider choice: price, quality, time to facility, and degree. Each provider profile was assigned a level from each attribute and each choice-set was assigned two provider profiles.

In order to isolate the causal effect of each attribute level (e.g., the impact of 5-stars compared to 3-stars on provider choice), it is important to ensure that each attribute level is balanced on (1) the levels of other attributes in the provider profile (e.g., 5-stars and 3-stars are combined with 100 rupees in an equal number of profiles), and (2) the attributes of the comparison profile (e.g., 5- 
stars is compared to a profile with 100 rupees equally as often as 3-stars is compared to a profile with 100 rupees). If there is imbalance on (1) or (2), comparison of different attribute levels could be confounded by this imbalance. For example, if 5-stars is more frequently paired with lower prices than 3-stars, then it becomes complicated to disentangle whether people have a preference for 5-stars over 3-stars, or if this difference is simply driven by a preference for lower prices. In order to achieve balance on (1) and (2) above, we randomly assigned provider attributes to provider profiles and provider profiles to choice-sets (a combination of two providers to choose from). Prior to field work, we constructed 8 randomly assigned blocks, each of which consisted of 8 choicesets (128 profiles in total). To create each block, we randomly sampled 16 profiles from the universe of possible profiles and used those profiles to construct 8 choice sets. We excluded choice sets where one profile dominated the other (i.e., at least as good on all attributes) to improve statistical power. We programmed the survey software to randomly assign respondents to one of the blocks, and we presented respondents with all 8 choice sets that corresponded to the respective block. We also randomized the order of the choice sets to avoid response fatigue bias, and the order of the two doctors within a choice set to avoid first response bias. Appendix Figure C1 shows an example choice-set with doctor A having a price of 100 rupees, a 5-star quality rating, 30 minutes of travel, and an Ayurvedic degree, and doctor B having a price of 200 rupees, a 3-star quality rating, 60 minutes of travel, and an MBBS/MD degree.

\section{Technical Quality Rating (star system)}

The survey team asked respondents to assume that the Ministry of Health had visited all of the health facilities in their area and provided a single quality rating based on the technical quality of the provider (e.g., prescribe the correct treatment, appropriate diagnosis, run all the correct tests, properly disinfect equipment, etc.). The quality rating was reflected using a star system: 5 stars represents perfect quality (e.g., correctly diagnoses illness and provides correct treatments) and 1 star represents very poor quality (e.g., provides wrong diagnoses and treatments). Three stars means the provider is not "very poor quality" or "perfect quality” but somewhere in the middle. 
Analysis of DCE

In expectation, the randomization procedure described above leads to balance across attribute levels. With perfect balance, one can simply compare the probability of choice across the different attribute levels to estimate the causal effect of switching between attribute levels on provider choice (e.g., the effect of an increase in quality from 3-stars to 5-stars). However, in practice, randomization does not always lead to perfect balance. To address any potential confounding introduced by imperfect balance, we include a set of choice-set fixed-effects in our regression model, which holds constant any differences across choice-sets and estimates the impact of attribute level changes within choice-sets. For, example, a change in price from 100 to 200 rupees might have a smaller effect on choice if the providers in the choice set are particularly strong on other attributes, and choice-set fixed-effects adjust for this. To identify the effect of each provider attribute on the probability of provider choice, we estimate the following linear probability model:

$$
\begin{aligned}
& \text { Choice }_{i c}=\lambda_{c}+\beta_{1} 100_{i c}+\beta_{2} 200_{i c}+\beta_{3} 300_{i c}+\theta_{1} 20_{i c}+\theta_{2} 30_{i c}+\theta_{3} 60_{i c}+ \\
& \alpha_{1} \text { stars }_{i c}+\alpha_{2} \text { stars }_{i c}+\rho_{1} \text { MBBS }_{i c}+\rho_{2} \text { ayurvedic }_{i c}+\rho_{3} \text { homeopathic }_{i c}+\epsilon_{i c}
\end{aligned}
$$

Where Choice is an indicator for whether profile $i$ of choice-set $c$ was chosen. The $\beta$ s represent the impact of switching from zero price to 100,200 , or 300 rupees on provider choice, the $\theta \mathrm{s}$ represent the impact of switching from 10 minutes travel time to 20,30, or 60 minutes of travel time, the $\alpha$ s represent the impact of switching from 1-star to 3 or 5 stars, and the $\rho$ s represent the impact of switching from no degree to MBBS, ayurvedic, or homeopathic degrees. The $\lambda_{c}$ term is a set of choice-set fixed-effects, which adjust for fixed differences between choice-sets.

\section{DCE Results}

Figure 1 displays the coefficients from equation 1 (full regression results in Appendix Table A9 and characteristics of DCE respondents in Appendix Table A11). Technical quality of the provider and the provider's medical training stand out as the most important provider attributes. Switching from a provider quality rating of 1-star to a 3-star rating increased the probability of choosing that provider by 33.9 percentage points (95\% CI 29-39, $\mathrm{p}<0.01$ ), and switching from a 3-star rating to a 5 -star rating increased the probability of choosing that provider by 30.4 percentage points ( $95 \%$ 
CI 26-35, $\mathrm{p}<0.01)$. Switching from no degree to an MBBS/MD degree increased the probability of choice by 79.2 percentage points (95\% CI 73-85, $\mathrm{p}<0.01$ ). The provider fee (price) and the time to arrive at the facility were of less importance. Respondents had a slight preference for cheaper providers; 100 rupees was preferred to 200 rupees ( 7.8 percentage point increase in choice probability) and 300 rupees (9.1 percentage point increase in choice probability). However, respondents did not like free providers, and preferred 100, 200, and 300 rupees to free. Respondents also had a slight preference for closer facilities (5.9, 7.9, and 9.3 percentage point increase in choice probability for 30, 20, and 10 mins of travel compared to 60 mins of travel, respectively).

\section{Willingness to Pay for Better Quality}

We used standard willingness to pay (WTP) techniques, to examine the additional money and time that people would spend for a provider with better technical quality and better training (Kleinman et al., 2002, Zanolini, et al., 2018). This analysis requires the assumption that preferences for providers are linear in price and time to facility. That is, this assumes that increasing the price from 100 to 200 has the same effect on probability of choosing a provider as increasing the price from 200 to 300. For our main analysis, we estimate the role of price and time non-parametrically, which does not require this assumption (equation 1). While figure 3 demonstrates that preferences appear linear in time to facility, there is a clear non-linearity in the relationship between prices and provider choice; all positive prices are preferred to free, but conditional on a positive price, lower prices are preferred. However, if we condition on positive prices, the relationship between the

effect of price on choice does appear linear. Therefore, when we estimate willingness to pay, we model price as a continuous variable while controlling for the effect of a provider being free using a discrete binary variable that indicates if the provider was free. This takes the following form.

$$
\begin{aligned}
& \text { Choice }_{i c}=\lambda_{c}+\beta_{1} \text { free }_{i c}+\beta_{2} \text { Price }_{i c}+\text { OTime }_{i c}+\alpha_{1} \text { stars }_{i c}+\alpha_{2} \text { stars }_{i c}+ \\
& \rho_{1} \text { MBBS }_{i c}+\rho_{2} \text { ayurvedic }_{i c}+\rho_{3} \text { homeopathic }_{i c}+\epsilon_{i c}
\end{aligned}
$$

Where free is an indicator for whether a provider was free or had a positive price, Price is a continuous variable ranging from 0 to 300 rupees and Time is a continuous variable ranging from 10 to 60 minutes. All other terms are identical to equation 1 . To estimate the additional price that 
someone would pay for 3-stars or 5-stars relative to 1-star, we divide the $\alpha$ 's by $\beta_{2}$. This represents the increase in price necessary to affect choice of provider to the same degree as switching from 1-star to 3- or 5-stars. Similarly, to estimate the additional time people would be willing to spend travel to a better quality facility, we divide the $\alpha$ 's by $\theta$. We carry out an identical process to estimate the WTP for an MBBS degree, substituting the $\alpha$ 's for $\rho$ 's. The coefficient estimates are in table $\mathrm{C} 2$ below.

We find that people are willing to pay an additional 772 rupees (roughly \$10) for 3 stars compared to 1 star, 1,464 (roughly \$20) rupees for 5 stars compared to 1 star, and 1,820 rupees (roughly \$25) for an MBBS degree over no degree. Similarly, if we assume time to facility is linearly related to preferences, people would travel 3 extra hours for 3 stars compared to 1 star, 5.5 extra hours for 5 stars compared to 1 star, and nearly 7 extra hours for an MBBS degree compared to no degree.

It is important to note that the linearity assumption is a fairly restrictive approximation of real choice behavior, and therefore results should be interpreted with caution. While the magnitude of these estimates is likely imprecise, overall, these results imply that people are willing to pay substantially more and travel much further for better technical quality of care from a well-trained provider.

\section{Quality and prices}

\section{Standardized patients}

We used data from a Standardized Patient (SP) experiment which involved an actor posing as a father seeking treatment for his ill 2-year-old child (see Appendix B for discussion of benefits and validity of SP method). This pattern of health care, in which a family member seeks care on behalf of the sick patient, is common in India and enables use of SP methods without putting a child at risk. The SP data used for this study has been documented in detail elsewhere (Mohanan et al., 2016, Mohanan et al., 2017, Mohanan, et al., 2015). Actors or SPs visited an average of 40 different providers ( $\min =30, \max =47$ ) and presented a case of a child with diarrhea or pneumonia (each provider was only visited by one SP). For the diarrhea case, each SP informed the provider that their 2-year old boy had been having loose stool for two days, passed stool 8-9 times the prior 
night, and had been crying too. Other symptoms were designed to match a case of rotavirus infection with no clinical signs of dehydration, and for which treatment guidelines consist of oral rehydration salts (ORS) and zinc (USAID/UNICEF/WHO, 2005). For the pneumonia case, SPs informed the provider that their 2-year-old son had been suffering from a fever and cough for five days with some vomiting. The symptoms were designed to match a case of bacterial pneumonia, for which the treatment guidelines are antibiotics (see Appendix B for full SP scripts). Immediately after the interaction, SPs were debriefed using exit interviews that recorded details of the interaction including the diagnosis, treatment provided, all fees, and their perception of the patientprovider interaction. Providers were all located in rural Bihar (provider sampling is described in the Appendix B). Each provider completed a survey that captured information on the characteristics of the health care practitioners (See Appendix Table A10 for provider characteristics).

\section{Provider Performance Measures}

We used three different categories of provider performance measures. The first was technical quality (e.g., adherence to clinical treatment guidelines), which is the most important element of quality for health outcomes. The second was the patient's assessment of provider interaction (e.g., did the provider appear knowledgeable, have good bedside manner, etc.). The third was provider effort.

\section{$\underline{\text { Technical Quality Measures }}$}

Our first technical quality measure was whether the provider explained the diagnosis of the child's illness correctly. For the rotavirus cases, we note a correct diagnosis if the provider explained to the patient that the child had diarrhea and no other illness. Although a diagnosis of diarrhea may seem trivial when a patient indicates that a child has loose stool, it is still important that the provider gives a diagnosis and explains to the patient that the diarrhea is not a symptom of another illness (e.g., malaria). We considered a diagnosis for pneumonia correct if the provider explained to the patient that the child had pneumonia and no other illness. If a provider gave no diagnosis, we coded this as incorrect. 
Next, we used a measure for whether the provider dispensed correct treatment. For the rotavirus case, we defined correct treatment as ORS (with or without zinc supplements), with no prescription of unnecessary or potentially harmful drugs according to the 2005 World Health Organization (WHO) guidelines (Child et al., 2005). In addition to an indicator for correct treatment, we created separate measures for whether ORS was given (regardless of additional treatments) and whether any antibiotics were given. ORS is the most essential treatment for child diarrhea, whereas antibiotics are inappropriate for diarrhea caused by rotavirus. For pneumonia, we defined correct treatment to include antibiotics with no harmful treatment.

Finally, SPs recorded whether providers asked a series of key diagnostic questions about the child's illness, which we used to create an index that captured the number of key questions asked (maximum of 5 for diarrhea and 3 for pneumonia). See Appendix table A1 for the list of essential questions and share of providers that asked each question.

\section{$\underline{\text { Patient Assessment of Provider Interaction }}$}

SPs were trained to report on their subjective opinions about the provider. We used indicators for whether the SP reported that they "liked" the provider and whether they would "go to this provider again” as proxies for how the SP perceived the quality of the interaction with the provider. In addition, SPs rated the provider on several characteristics associated with the visit on 1-4 scales: 1) environment, 2) knowledge, 3) takes patient seriously, 4) explanation. We used these ratings to construct a global assessment index, which is a composite score that represents the average across all four ratings. This index captures whether the SP perceived the visit as good "quality" or the patient centeredness of the provider.

\section{$\underline{\text { Provider Effort Measures }}$}

We use two measures of provider effort. First, we use the length of the visit with the SP. Second, we use the total number of medical history questions asked by the provider. 


\section{Analysis of Returns to Provider Performance}

We relate the fee charged by the provider for the SP consultation (reported by the SP) to each of the provider performance measures described above. The fee only includes the cost of the consultation (e.g., treatment costs are excluded) to avoid introducing a spurious correlation. ${ }^{1}$ We estimate the following cross-sectional linear regression of the provider fee on the quality received by the SP, controlling for provider characteristics (age, sex, years of experience, training, and whether the facility has electricity) and SP fixed-effects:

(3) $f e e_{i}=\beta_{0}+\beta_{1} Q_{i}+\boldsymbol{X}_{i} \boldsymbol{\beta}_{2}+\alpha+\epsilon_{i}$

Where $f e e_{i}$ represents the fee charged by doctor $i$ for the visit, $Q$ indicates the respective provider performance metric, $\boldsymbol{X}$ is a vector of provider characteristics (age, sex, years of experience, training, and whether the facility has electricity) that serve to control for potential confounding factors that could be correlated with both price and quality, and $\alpha$ is a set of SP fixed-effects to control for differences between SPs (robustness to covariate selection examined below). The coefficient of interest is $\beta_{1}$, which estimates the association between a provider performance metric and the provider fee.

\section{Association between quality and price}

Table 2 presents summary statistics for our main dependent and explanatory variables. The average price charged by the provider (as reported by the SP) was 44.5 INR for a diarrhea case (interquartile range (IQR) of 20 to 60 INR) and 73.5 INR for a pneumonia case (IQR of 2 to 125 INR; see Appendix Figure A1 for complete distributions). Providers performed very poorly on our measures of technical quality. For diarrhea, only 3\% of providers gave the correct diagnosis, no providers provided the correct treatment, and only $13 \%$ provided ORS. Moreover, $82 \%$ of providers gave antibiotics, which is inappropriate for the case presented. For pneumonia, 9\% of providers gave a correct diagnosis and 14\% gave correct treatment. Although $63 \%$ of providers dispensed antibiotics for pneumonia cases, which is the correct treatment, most (49\%) gave harmful medications along with antibiotics.

\footnotetext{
${ }^{1}$ The overall price is endogenous to the treatment provided. Using only the provider fee avoids this confound.
} 
Regardless of the poor technical quality, patient assessment of providers was fairly high. Three quarters of providers were "liked" by the SP (for both conditions), and the SP indicated that they would return to the provider for $60 \%$ and $75 \%$ of cases for diarrhea and pneumonia, respectively. The visits were very short with an average of under two minutes for both conditions, and the providers asked an average of two to three medical history questions.

\section{Returns to Technical Quality}

Figure 2 presents results from equation (3); the association between the three provider performance metric categories and the price charged by the provider to the SP (full regression results in Appendix Tables A2-A7). Each point represents the coefficient from our linear probability model and error bars represent 95\% confidence intervals. For diarrhea cases, there is no association between prices and most of our measures of technical quality as confidence intervals pass through zero. However, there does seem to be some financial reward to asking essential diagnostic questions; estimate of 9.3 rupees (15 cents USD) for each additional question (95\% CI 4.5 to 14.1; $\mathrm{p}$-value $<0.01)$. Finally, we also find a positive association between prices and inappropriate antibiotic prescriptions for child diarrhea. Providers that prescribed antibiotics were able charge an extra 21.9 rupees (83\% increase; 95\% CI 9.6 to 35.3 , p-value $<0.01)$.

We observed similar patterns for pneumonia cases. Prices were not associated with correct diagnosis or correct treatment, but were associated with asking more essential diagnostic questions; estimate of 16.6 rupees for each additional question (95\% CI 6.4 to 26.8; p-value<0.01).

\section{Returns to Patient Assessment of Provider Interaction}

We find a strong association between patient assessment of providers and prices. Providers that were "liked" by the SP charged an average of 19.1 rupees (95\% CI 7.8 to 30.1 ; p-value $<0.01$ ) and 27.2 rupees (95\% CI 0.02 to 54.3 ; p-value $=0.05)$ more for diarrhea cases and pneumonia cases, respectively (64\% and 52\% increases, respectively). Moreover, if an SP reported that they would return to a provider, the provider was able to charge a higher price (27.1 additional rupees for diarrhea cases (96\% increase) and 29.1 additional rupees for pneumonia cases (58\% increase)). For the global assessment index, which measures the SP's perception of quality, a one unit increase 
in the index is associated with an increase in price of 43.9 rupees for diarrhea cases (95\% CI 29.4 to 58.4, p-value $<0.01$ ) and 25.2 rupees for pneumonia cases (95\% CI -2.8 to 53.2, p-value $=0.08)$.

Returns to Provider Effort

Providers that put in more effort were able to charge higher prices. Each additional minute spent with the SP was associated with 8.2 additional rupees for diarrhea and 21.2 additional rupees for pneumonia. Each additional medical history question asked was associated with an extra 5.6 rupees for diarrhea and 7.3 rupees for pneumonia.

\section{Pooling illnesses}

Pooling diarrhea and pneumonia SP visits allows us to estimate the associations described above with greater statistical power. When we do so (Figure 2C), our estimates are more precise and demonstrate a similar pattern to individual illnesses: no financial returns for technical quality but positive returns to provider performance measures that are observable to the patient (patient assessment and provider effort).

\section{Robustness Checks}

\section{Sensitivity of results to covariate selection}

We chose covariates for the model which are theoretically expected to be correlated with the provider fees. However, covariate selection can have a large impact on the coefficients of interests depending on correlations with our quality measures. In order to test the sensitivity of our results to different covariate combinations, we re-ran our models using every possible combination of the 6 covariates we include in our model (provider's age, sex, degree, years of experience, whether the facility has electricity, and whether the provider asked the client to return with the child). This resulted in 64 regressions per quality measure (including an unadjusted model). We included SP fixed-effects in all models. Figure A7 plots the range of 64 coefficients and p-values for each quality measure. The ends of the p-value range do not cross the 0.05 or the 0.1 threshold for any 
of our quality metrics. This suggests that our results and conclusions are robust to choice of covariates in our models.

Sensitivity of results to model selection

Many of the SP-provider interactions had a zero provider fee (see Appendix Figure A1). While a non-normal distributed outcome variable does not bias the results of our OLS models, other models could be more appropriate for fitting the data. We tested the sensitivity of our results to model selection by estimating the relationships of interest using a generalized linear model with a log link. Figure A4 plots the coefficients from this analysis and results are largely unchanged. In addition, we conducted our main analysis excluding zero prices and results are also largely unchanged (Figure A5).

Does choosing providers based on interpersonal quality lead to better technical quality?

Our main result that people want to choose providers based on technical quality, but technical quality does not predict prices. Only elements of quality that can be observed by the patient predict prices. This suggests that people have incomplete information on provider quality and only use observable quality metrics to make choices, which are less important for health outcomes. However, this might not pose a problem for the public's health if observable quality metrics are highly correlated with technical quality metrics. Table 3 presents the share of providers with good technical quality metrics by whether they received good observable quality metrics. Observable quality was modestly predictive of technical quality; providers that received good patient ratings were about 13 percentage points more likely to provide ORS, 3-4 percentage points more likely to provide the correct treatment, and 5-8 percentage points more likely to provide the correct diagnosis. However, choosing providers based on interpersonal quality would fall far short of achieving good technical quality outcomes for most patients; over $80 \%$ of providers with good patient ratings did not provide ORS, over 91\% provided the wrong treatment, and over 91\% gave the wrong diagnosis. Moreover, providers with good patient ratings were 11-20 percentage points more likely to provide antibiotics inappropriately. 


\section{Replicating analyses with different data set}

To assess the external validity of our results and to compare with prior work on the price/quality relationship, we conducted our same analysis using the SP data from Das et al. (2016) (Das, et al., 2016b). These SPs carried out similarly structured visits posing as a caretaker for a child with diarrhea, asthma, and unstable angina in 5 districts in the Indian state of Madhya Pradesh. We conducted the same analysis described above (equation 3) using these data. Appendix Figure A2 demonstrates that results are very similar when we use this alternative source of SP data; no association between prices and correct treatment, correct diagnosis, or ORS, but a price premium for more provider effort and inappropriate antibiotic prescription.

\section{Discussion}

In order to design policy that leads to improved quality of care in LMICs it is essential to first understand what drives quality in the private sector and why patients seek care from providers that provide poor quality care. This study presents several key insights. First, we demonstrate that although private providers can charge higher prices for good patient interactions and for putting in more effort, they are not able to charge higher prices for providing good technical quality correctly diagnosing and treating illness. Second, even though good patient assessments and effort are positively correlated with technical quality, over $90 \%$ of patients still receive care from providers with poor technical quality. Third, the market rewards effort and patient assessment even when technical quality is poor or non-existent. Fourth, the market sometimes rewards poor quality care such as inappropriate prescribing of antibiotics and other harmful treatments. Juxtaposing these findings with the fact that correct diagnosis and treatment are key for improving health outcomes suggests that market forces are not rewarding inputs that are critical for improvements in health through prices.

This lack of a business case for quality is not unique to LMICs, and even research from the US highlights the lack of financial returns to improving quality. Leatherman et al. 2003 use case studies to analyze the business case for quality improvement (Leatherman et al., 2003). They find that, in the short run, financial returns to implementing even proven high value interventions are negative. Across all case studies they find that consumers were unable to discern quality 
differences and thus firms implementing quality improvement efforts did not see an increase in market share.

Just like the evidence from the US, we also demonstrate that the lack of market returns to technical quality likely stem from consumers not being able to discern good quality care from bad quality care. Our results suggest that caretakers are unable to distinguish between providers based on technical quality and instead reward providers based on elements of provider performance that they are able to observe (e.g., effort and positive interactions). Providers were also rewarded for providing antibiotics inappropriately, suggesting that patients could perceive antibiotic provision as good technical quality. The market inefficiency is not a result of patients not valuing technical quality. In fact, patients would pay more and travel farther for providers that have good technical quality ratings.

Quality of care is generally very poor in the private health sector in India, especially so in the informal sector, and it is not immediately clear that these providers are capable of providing good technical quality. If this is the case, then increasing returns to quality will have little effect on provider behavior. While some interventions to improve provider capacity have proven successful, others have failed (Das et al., 2016a, Mohanan, et al., 2016, Mohanan, et al., 2017). Moreover, regulation of the private sector is particularly difficult, given that many of these providers are unregistered and informal. However, given the large market share of the private sector - the private sector accounts for over 70\% of diarrhea care in India (DHS, 2016) - we cannot give up on finding ways of engaging the private sector to improve quality. In a recent National Academy of Sciences report, a panel of experts suggested that private sector engagement plays a crucial role in improving quality of care in LMICs (National Academies of Sciences, 2018).

Although provider inadequacy likely exists among our sample of providers, most appear capable of providing good technical quality, at least for simple cases like diarrhea and pneumonia. For example, over $70 \%$ of providers in our sample indicated in a vignette that they would provide ORS for a case of child diarrhea (Mohanan, et al., 2015), when only 13\% did so in practice (Table 2). This suggest that many providers in our sample are capable of providing better quality if there were an incentive to do so. 
There are several challenges in resolving this failure of markets to reward quality. First, we need to systematically collect information on technical quality of providers. This can be a daunting task in LMICs with a large informal sector and poor record keeping. Perhaps, governments can use the SP method we used in this study to collect information on quality. However, there are many thousands of primary health care providers in most Indian states. Thus, using the SP method on such a large scale would be logistically challenging and quite costly. There is potential for private enterprise to fill this gap with technology-based solutions that solicit quality information from real patients after a visit. The move towards universal health coverage might also provide an opportunity to use administrative data from national health plans to measure quality or make routine collection of quality data a necessary condition for provider reimbursement under universal health coverage. Once quality data is collected, the next challenge is making this information publicly available. In the US, government websites provide star ratings for hospitals, health plans, nursing homes, and physicians. The available evidence from the US on the impact of public reporting on provider choice and quality is mixed (Fung et al., 2008). While there is evidence that public reporting improves hospital quality, the effect of public reporting on patient choice of provider is inconsistent. The evidence on public reporting from LMICs is also limited. We know of only two cluster randomized studies from China that found that public reporting of prescribing patterns can reduce inappropriate use of antibiotics (Tang et al., 2016, Yang et al., 2014). Evidence from the US suggests that behavioral economics interventions (peer comparison and justification) can be useful for reducing inappropriate antibiotics prescriptions (Meeker et al., 2016). Such interventions should be explored in an LMIC context.

The limited information on effectiveness of public reporting of quality does not mean that consumer engagement to use quality information to drive provider choice is not possible. Perhaps, merely reporting quality data on a website is not enough. More needs to be done to engage consumers in using quality information. One option might be to post letter grades for health care facilities in patient waiting rooms or on other locations visible to the public. Such a strategy has worked in influencing patient choices in the restaurant industry (Jin and Leslie, 2005). Another option might be to develop mobile or text messaging applications so that consumers can get quality information when they are making provider choice decisions. Although startup companies in India 
are working on such solutions, more research is needed on testing new and innovative approaches to consumer engagement and public reporting.

Another option is to focus on the demand-side and train patients how to discern good and bad quality themselves. This could be particularly effective when good technical quality is simple and easy to observe, such as providing ORS for child diarrhea. However, ORS has been the gold standard treatment for child diarrhea for nearly 4 decades and successful social marketing campaigns have led to very high awareness (Kassegne et al., 2011, Lenters et al., 2013, Rao et al., 1998). In 2016, over 85\% of women in India had heard of ORS, but only half of cases were treated with ORS (DHS, 2016). Thus, it is not clear that simply informing patients on what good technical quality looks will have a large effect on quality of care received for diarrhea.

The findings of our study should be considered in light of its limitations. First, our analysis of how the market rewards quality is cross sectional and therefore fails to identify the causal effect of how changes in quality affect price. Future work should aim to exploit random variation in quality to better identify the causal effect of quality on price. Second, good technical quality was rare, and therefore our estimates of the association between price and treatment/diagnosis were imprecise. Third, our analysis of patient preferences for provider attributes were self-reported by the caretakers in hypothetical scenarios. It is possible that these caretakers would reveal different preference when actually choosing a provider. Fourth, providers could be rewarded by the market in other ways aside from prices, such as increased client volume. Therefore, our analysis of prices could miss important market rewards for providing good technical quality. Fifth, it is possible the preferences for quality we identify in the DCE do not directly map to the measurement of quality in the SP experiment. While we included correct treatment and diagnosis in the description of the star system, we also included other aspects of quality that we do not measure in the SP experiment (e.g., properly disinfect equipment). Sixth, our DCE design does not assess preferences for inappropriate treatments, such as antibiotics. Patients could inaccurately believe such treatments are good quality and choose providers accordingly. Seventh, our DCE sample was selected from urban Bihar (for budgetary reasons) whereas our SP visits were in rural Bihar. It is possible preferences are different in urban and rural settings. Finally, our results might not be applicable to other settings or other illnesses. However, we find very similar results for four different illnesses 
(diarrhea and pneumonia in Figure 2 and asthma and angina in Figure A2) and in two different states in India (Bihar and Madhya Pradesh). Nonetheless, results might be different for chronic or adult illness and in other LMCs.

Achieving the goal of universal health coverage will have limited effects on health if quality of care remains poor in LMICs (Das, et al., 2018). We show that although patients value quality more so than other provider attributes, they appear unable to choose providers based on technical quality. This suggests that collecting and disseminating information on the technical quality of providers could be one mechanism for quality improvement. Doing so has the potential to shift demand to higher quality providers, incentivize providers to perform better, and improve health. 


\section{References}

Alkire, Blake C; Alexander W Peters; Mark G Shrime and John G Meara. 2018. "The Economic Consequences of Mortality Amenable to High-Quality Health Care in Low-and Middle-Income Countries." Health affairs, 37(6), 988-96.

Andaleeb, Syed Saad; Nazlee Siddiqui and Shahjahan Khandakar. 2007. "Patient Satisfaction with Health Services in Bangladesh." Health policy and planning, 22(4), 263-73.

Arrow, Kenneth J. 1963. "Uncertainty and the Welfare Economics of Medical Care." The American economic review, 53(5), 941-73.

Banerjee, Abhijit; Angus Deaton and Esther Duflo. 2004. "Health, Health Care, and Economic Development: Wealth, Health, and Health Services in Rural Rajasthan." The American economic review, 94(2), 326.

Basu, Sanjay; Jason Andrews; Sandeep Kishore; Rajesh Panjabi and David Stuckler. 2012. "Comparative Performance of Private and Public Healthcare Systems in Low-and Middle-Income Countries: A Systematic Review." PLoS medicine, 9(6), e1001244.

Berendes, Sima; Peter Heywood; Sandy Oliver and Paul Garner. 2011. "Quality of Private and Public Ambulatory Health Care in Low and Middle Income Countries: Systematic Review of Comparative Studies." PLoS medicine, 8(4), e1000433.

Child, World Health Organization. Department of; Adolescent Health; World Health Organization and UNICEF. 2005. Handbook Imci: Integrated Management of Childhood Illness. World Health Organization.

Das, Jai K; Rehana A Salam and Zulfiqar A Bhutta. 2014. "Global Burden of Childhood Diarrhea and Interventions." Current Opinion in Infectious Diseases, 27(5), 451-58.

Das, Jishnu; Abhijit Chowdhury; Reshmaan Hussam and Abhijit V Banerjee. 2016a. "The Impact of Training Informal Health Care Providers in India: A Randomized Controlled Trial." Science, 354(6308), aaf7384.

Das, Jishnu; Jeffrey Hammer and Kenneth Leonard. 2008. "The Quality of Medical Advice in LowIncome Countries." The Journal of Economic Perspectives, 93-114.

Das, Jishnu; Alaka Holla; Veena Das; Manoj Mohanan; Diana Tabak and Brian Chan. 2012. "In Urban and Rural India, a Standardized Patient Study Showed Low Levels of Provider Training and Huge Quality Gaps." Health affairs, 31(12), 2774-84.

Das, Jishnu; Alaka Holla; Aakash Mohpal and Karthik Muralidharan. 2016b. "Quality and Accountability in Health Care Delivery: Audit-Study Evidence from Primary Care in India." American Economic Review, 106(12), 3765-99.

Das, Jishnu; Liana Woskie; Ruma Rajbhandari; Kamran Abbasi and Ashish Jha. 2018. "Rethinking Assumptions About Delivery of Healthcare: Implications for Universal Health Coverage." BMJ, 361, $\mathrm{k} 1716$.

DHS. 2016. "India Demographic and Health Survey 2016," I. M. o. H. a. F. Welfare,

Dupas, Pascaline and Edward Miguel. 2017. "Impacts and Determinants of Health Levels in Low-Income Countries," Handbook of Economic Field Experiments. Elsevier, 3-93.

Fung, Constance H; Yee-Wei Lim; Soeren Mattke; Cheryl Damberg and Paul G Shekelle. 2008. "Systematic Review: The Evidence That Publishing Patient Care Performance Data Improves Quality of Care." Annals of internal medicine, 148(2), 111-23.

Grépin, Karen A. 2016. "Private Sector an Important but Not Dominant Provider of Key Health Services in Low-and Middle-Income Countries." Health affairs, 35(7), 1214-21.

Hanson, Kara; Barbara McPake; Pamela Nakamba and Luke Archard. 2005. "Preferences for Hospital Quality in Zambia: Results from a Discrete Choice Experiment." Health economics, 14(7), 687701.

Jin, Ginger Zhe and Phillip Leslie. 2005. "The Case in Support of Restaurant Hygiene Grade Cards." Choices, 20(2), 97-102. 
Kassegne, Sethson; Megan B Kays and Jerome Nzohabonayo. 2011. "Evaluation of a Social Marketing Intervention Promoting Oral Rehydration Salts in Burundi." BMC public health, 11(1), 155.

Kim, Sung Soo; Stan Kaplowitz and Mark V Johnston. 2004. "The Effects of Physician Empathy on Patient Satisfaction and Compliance." Evaluation \& the health professions, 27(3), 237-51.

Kitapci, Olgun; Ceylan Akdogan and Ibrahim Taylan Dortyol. 2014. "The Impact of Service Quality Dimensions on Patient Satisfaction, Repurchase Intentions and Word-of-Mouth Communication in the Public Healthcare Industry." Procedia-Social and Behavioral Sciences, 148, 161-69.

Kleinman, Leah; Emma McIntosh; Mandy Ryan; Jordana Schmier; Joseph Crawley; G Richard Locke and Gregory De Lissovoy. 2002. "Willingness to Pay for Complete Symptom Relief of Gastroesophageal Reflux Disease." Archives of internal medicine, 162(12), 1361-66.

Kremer, Michael and Rachel Glennerster. 2011. "Improving Health in Developing Countries." Handbook of Health Economics, 2, 201-315.

Kruk, Margaret E; Anna D Gage; Catherine Arsenault; Keely Jordan; Hannah H Leslie; Sanam Roder-DeWan; Olusoji Adeyi; Pierre Barker; Bernadette Daelmans and Svetlana V Doubova. 2018. "High-Quality Health Systems in the Sustainable Development Goals Era: Time for a Revolution." The Lancet Global Health, 6(11), e1196-e252.

Lagarde, Mylene and Natasha Palmer. 2008. "The Impact of User Fees on Health Service Utilization in Low-and Middle-Income Countries: How Strong Is the Evidence?" Bulletin of the World Health Organization, 86, 839-48C.

Leatherman, Sheila; Donald Berwick; Debra Iles; Lawrence S Lewin; Frank Davidoff; Thomas Nolan and Maureen Bisognano. 2003. "The Business Case for Quality: Case Studies and an Analysis." Health affairs, 22(2), 17-30.

Lenters, Lindsey M; Jai K Das and Zulfiqar A Bhutta. 2013. "Systematic Review of Strategies to Increase Use of Oral Rehydration Solution at the Household Level." BMC public health, 13(3), S28.

Meeker, Daniella; Jeffrey A Linder; Craig R Fox; Mark W Friedberg; Stephen D Persell; Noah J Goldstein; Tara K Knight; Joel W Hay and Jason N Doctor. 2016. "Effect of Behavioral Interventions on Inappropriate Antibiotic Prescribing among Primary Care Practices: A Randomized Clinical Trial." JAmA, 315(6), 562-70.

Mohanan, Manoj; Kimberly S Babiarz; Jeremy D Goldhaber-Fiebert; Grant Miller and Marcos Vera-Hernández. 2016. "Effect of a Large-Scale Social Franchising and Telemedicine Program on Childhood Diarrhea and Pneumonia Outcomes in India." Health affairs, 35(10), 1800-09.

Mohanan, Manoj; Soledad Giardili; Veena Das; Tracy L Rabin; Sunil S Raj; Jeremy I Schwartz; Aparna Seth; Jeremy D Goldhaber-Fiebert; Grant Miller and Marcos Vera-Hernández. 2017. "Evaluation of a Social Franchising and Telemedicine Programme and the Care Provided for Childhood Diarrhoea and Pneumonia, Bihar, India." Bulletin of the World Health Organization, 95(5), 343.

Mohanan, Manoj; Marcos Vera-Hernández; Veena Das; Soledad Giardili; Jeremy D GoldhaberFiebert; Tracy L Rabin; Sunil S Raj; Jeremy I Schwartz and Aparna Seth. 2015. "The Know-Do Gap in Quality of Health Care for Childhood Diarrhea and Pneumonia in Rural India." JAMA pediatrics, 169(4), 349-57.

Murti, Arjun; Aashish Deshpande and Namita Srivastava. 2013. "Service Quality, Customer (Patient) Satisfaction and Behavioural Intention in Health Care Services: Exploring the Indian Perspective." Journal of Health Management, 15(1), 29-44.

National Academies of Sciences. 2018. "Crossing the Global Quality Chasm: Improving Health Care Worldwide," T. N. A. Press, Washington, DC:

National Academies of Sciences, Engineering and Medicine. 2019. Crossing the Global Quality Chasm: Improving Health Care Worldwide. National Academies Press.

Rao, K Vaninadha; Vinod K Mishra and Robert D Retherford. 1998. "Knowledge and Use of Oral Rehydration Therapy for Childhood Diarrhoea in India: Effects of Exposure to Mass Media."

Rethans, Jan-Joost; Ferd Sturmans; Riet Drop and Cees Van der Vleuten. 1991. "Assessment of the Performance of General Practitioners by the Use of Standardized (Simulated) Patients." Br J Gen Pract, 41(344), 97-99. 
Rethans, Jan-Joost; Simone Gorter; Lonneke Bokken and Linda Morrison. 2007. "Unannounced Standardised Patients in Real Practice: A Systematic Literature Review." Medical education, 41(6), 53749.

Robinson, James C; Christopher Whaley and Timothy T Brown. 2016. "Association of Reference Pricing for Diagnostic Laboratory Testing with Changes in Patient Choices, Prices, and Total Spending for Diagnostic Tests." JAMA internal medicine, 176(9), 1353-59.

Sood, Neeraj and Zachary Wagner. 2014. "Private Sector Provision of Oral Rehydration Therapy for Child Diarrhea in Sub-Saharan Africa." The American Journal of Tropical Medicine and Hygiene, 90(5), 939-44.

Sood, Neeraj; Zachary Wagner; Peter Huckfeldt and Amelia M Haviland. 2013. "Price Shopping in Consumer-Directed Health Plans," Forum for Health Economics and Policy. De Gruyter, 35-53.

Srivastava, Aradhana; Bilal I Avan; Preety Rajbangshi and Sanghita Bhattacharyya. 2015. "Determinants of Women's Satisfaction with Maternal Health Care: A Review of Literature from Developing Countries." BMC pregnancy and childbirth, 15(1), 97.

Tang, Yuqing; Chaojie Liu and Xinping Zhang. 2016. "Public Reporting as a Prescriptions Quality Improvement Measure in Primary Care Settings in China: Variations in Effects Associated with Diagnoses." Scientific reports, 6, 39361.

USAID/UNICEF/WHO. 2005. "Diarrhoea Treatment Guidelines: Including New Recommendations for the Use of Ors and Zinc Supplementation for Clinic-Based Healthcare Workers," Arlington, VA: USAID Micronutrient Program,

Wagner, Zachary; John Bosco Asiimwe; William H Dow and David I Levine. 2019. "The Role of Price and Convenience in Use of Oral Rehydration Salts to Treat Child Diarrhea: A Cluster Randomized Trial in Uganda." PLoS medicine, 16(1), e1002734.

Wagner, Zachary; Manan Shah and Neeraj Sood. 2014a. "Barriers to Use of Oral Rehydration Salts for Child Diarrhea in the Private Sector: Evidence from India." Journal of tropical pediatrics, 61(1), 37-43.

Wagner, Zachary; Peter G Szilagyi and Neeraj Sood. 2014b. "Comparative Performance of Public and Private Sector Delivery of Bcg Vaccination: Evidence from Sub-Saharan Africa." Vaccine, 32(35), 452228.

Whaley, Christopher; Jennifer Schneider Chafen; Sophie Pinkard; Gabriella Kellerman; Dena Bravata; Robert Kocher and Neeraj Sood. 2014. "Association between Availability of Health Service Prices and Payments for These Services." JAmA, 312(16), 1670-76.

World Health Organization. 2018. "Delivering Quality Health Services: A Global Imperative for Universal Health Coverage."

Yang, Lianping; Chaojie Liu; Lijun Wang; Xi Yin and Xinping Zhang. 2014. "Public Reporting Improves Antibiotic Prescribing for Upper Respiratory Tract Infections in Primary Care: A Matched-Pair Cluster-Randomized Trial in China." Health research policy and systems, 12(1), 61.

Zanolini, Arianna; Kombatende Sikombe; Izukanji Sikazwe; Ingrid Eshun-Wilson; Paul Somwe; Carolyn Bolton Moore; Stephanie M Topp; Nancy Czaicki; Laura K Beres and Chanda P Mwamba. 2018. "Understanding Preferences for Hiv Care and Treatment in Zambia: Evidence from a Discrete Choice Experiment among Patients Who Have Been Lost to Follow-Up." PLoS medicine, 15(8), e1002636.

Zhang, Xinke; Amelia Haviland; Ateev Mehrotra; Peter Huckfeldt; Zachary Wagner and Neeraj Sood. 2018. "Does Enrollment in High-Deductible Health Plans Encourage Price Shopping?" Health services research, 53, 2718-34. 


\section{Tables}

Table 1. Provider Attribute Levels for Discrete Choice Experiment

\begin{tabular}{|c|c|}
\hline Attributes & Levels \\
\hline Price & $\begin{array}{l}\text { Free } \\
100 \text { Rupees } \\
200 \text { Rupees } \\
300 \text { Rupees }\end{array}$ \\
\hline $\begin{array}{l}\text { Technical } \\
\text { Quality }\end{array}$ & $\begin{array}{l}1 \text { Star } \\
3 \text { Stars } \\
5 \text { Stars }\end{array}$ \\
\hline $\begin{array}{l}\text { Time to Arrive } \\
\text { at Facility }\end{array}$ & $\begin{array}{l}10 \text { Minutes } \\
20 \text { Minutes } \\
30 \text { Minutes } \\
60 \text { Minutes }\end{array}$ \\
\hline Degree & $\begin{array}{l}\text { No Degree } \\
\text { Ayurvedic } \\
\text { Homeopathic } \\
\text { MBBS/MD }\end{array}$ \\
\hline
\end{tabular}


Table 2. Price and Quality Summary Statistics

\begin{tabular}{|c|c|c|c|}
\hline & \multicolumn{3}{|c|}{ Illness presented by Standardized Patient } \\
\hline & $\begin{array}{l}\text { Diarrhea } \\
(\mathrm{N}=205)\end{array}$ & $\begin{array}{c}\text { Pneumonia } \\
(\mathrm{N}=205)\end{array}$ & $\begin{array}{c}\text { Pooled } \\
(\mathrm{N}=410)\end{array}$ \\
\hline \multirow[t]{2}{*}{ Provider Fee (rupees) } & 44.54 & 73.54 & 58.79 \\
\hline & (34.34) & (61.39) & (51.53) \\
\hline \multicolumn{4}{|l|}{ Technical Quality } \\
\hline \multirow[t]{2}{*}{ Correct Treatment } & 0.00 & 0.14 & 0.07 \\
\hline & $(0.00)$ & $(0.34)$ & $(0.25)$ \\
\hline \multirow[t]{2}{*}{ Correct Diagnosis } & 0.03 & 0.09 & 0.06 \\
\hline & $(0.17)$ & $(0.29)$ & $(0.24)$ \\
\hline \multirow[t]{2}{*}{ Provided ORS } & 0.13 & $\mathrm{n} / \mathrm{a}$ & 0.13 \\
\hline & $(0.33)$ & $\mathrm{n} / \mathrm{a}$ & $(0.33)$ \\
\hline \multirow[t]{2}{*}{ Provided Antibiotic } & 0.82 & 0.63 & 0.73 \\
\hline & $(0.38)$ & $(0.48)$ & $(0.45)$ \\
\hline \multirow[t]{2}{*}{ Inappropriate Antibiotics } & 0.82 & 0.49 & 0.66 \\
\hline & $(0.38)$ & $(0.50)$ & $(0.47)$ \\
\hline \multicolumn{4}{|l|}{ Patient Assessment } \\
\hline \multirow[t]{2}{*}{ Liked Provider } & 0.76 & 0.78 & 0.77 \\
\hline & $(0.43)$ & $(0.42)$ & $(0.42)$ \\
\hline \multirow[t]{2}{*}{ Would Return to Provider } & 0.60 & 0.75 & 0.67 \\
\hline & $(0.49)$ & $(0.43)$ & $(0.47)$ \\
\hline \multirow[t]{2}{*}{ Global Assessment Index (1-4) } & 1.77 & 1.9 & 1.83 \\
\hline & $(0.31)$ & $(0.36)$ & $(0.34)$ \\
\hline \multicolumn{4}{|l|}{ Provider Effort } \\
\hline \multirow[t]{2}{*}{ Length of Visit (Minutes) } & 1.62 & 1.71 & 1.66 \\
\hline & $(0.99)$ & $(0.91)$ & $(0.95)$ \\
\hline \multirow[t]{2}{*}{ Number of Questions } & 2.45 & 3.06 & 2.76 \\
\hline & $(1.84)$ & $(2.16)$ & $(2.03)$ \\
\hline
\end{tabular}

Source: Data comes from standardized patient reports conducted by Mohanan et al. (2015) 
Table 3. Share of providers that provided good technical quality at different levels of interpersonal quality

\begin{tabular}{cccccc}
\hline \hline & $\mathrm{N}$ & Correct Diagnosis & $\begin{array}{c}\text { Correct } \\
\text { Treatment }\end{array}$ & Provided ORS & $\begin{array}{c}\text { Provided } \\
\text { Antibiotics }\end{array}$ \\
\hline $\begin{array}{c}\text { High Global } \\
\text { Assessment Index }\end{array}$ & & & & & \\
Yes & 284 & $8.8 \%$ & $8.1 \%$ & $17.4 \%$ & $72.9 \%$ \\
No & 110 & $0.0 \%$ & $4.5 \%$ & $4.3 \%$ & $57.3 \%$ \\
Liked By SP & & & & & $70.7 \%$ \\
Yes & 314 & $7.6 \%$ & $7.3 \%$ & $16.1 \%$ & $50.0 \%$ \\
No & 96 & $1.0 \%$ & $5.2 \%$ & $2.0 \%$ & $68.8 \%$ \\
$\begin{array}{c}\text { SP Would Return } \\
\text { to Provider }\end{array}$ & & & & & $59.7 \%$ \\
Yes & 276 & $8.0 \%$ & $8.3 \%$ & $4.8 \%$ & $59 \%$ \\
No & 134 & $2.2 \%$ & $3.7 \%$ & & \\
\hline \hline
\end{tabular}

Percentages represent the share of providers for whom the SP reported the positive assessment indicated by the column header. High global assessment index implies the SP scored the provider above the median of 1.8.

Source: Data comes from standardized patient reports conducted by Mohanan et al. (2015) 


\section{Figures}

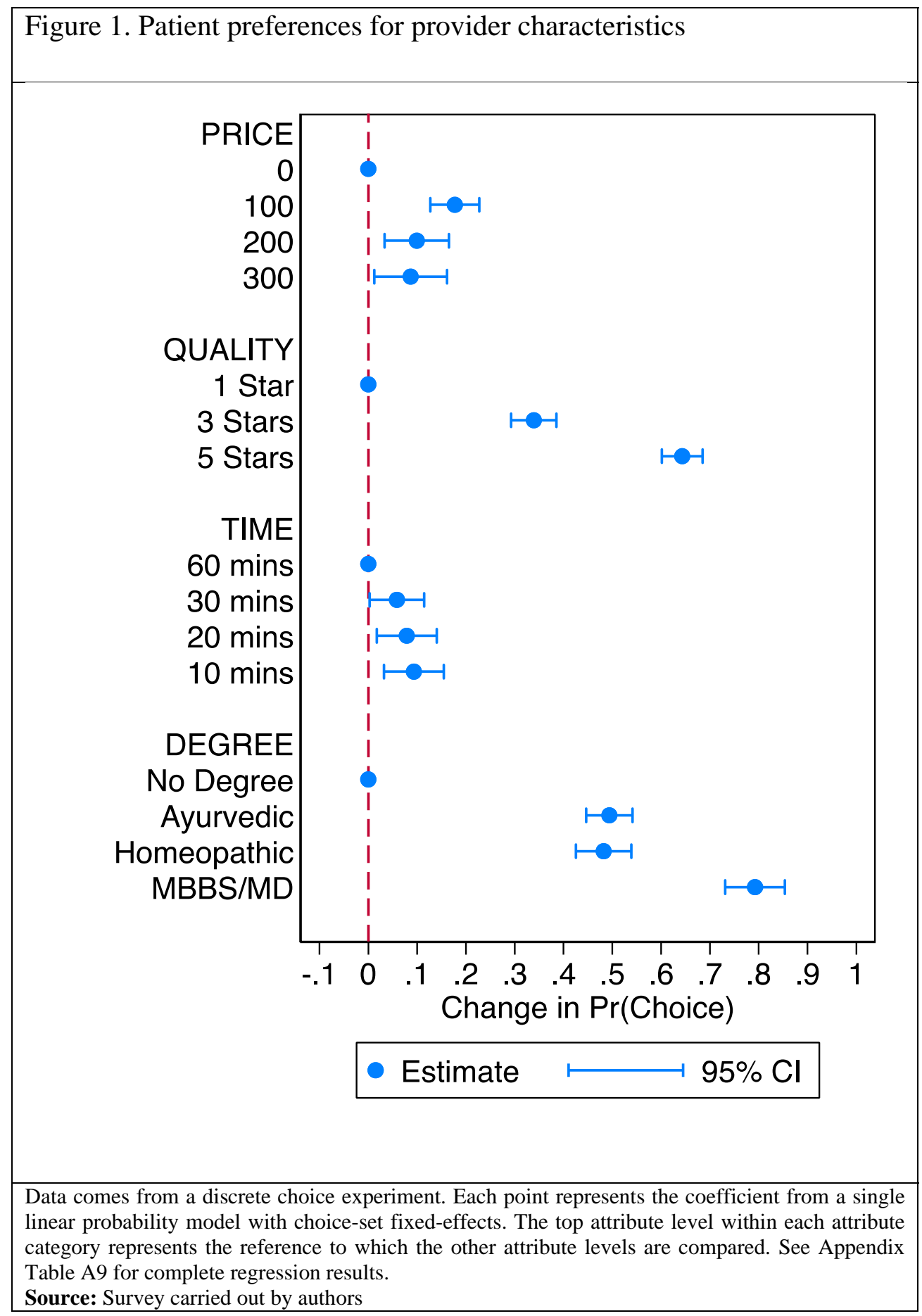




\begin{tabular}{|c|c|c|c|c|c|}
\hline \multicolumn{2}{|c|}{ A. Diarrhea } & \multicolumn{2}{|c|}{ B. Pneumonia } & \multicolumn{2}{|c|}{ C. Pooled } \\
\hline \multirow{15}{*}{$\begin{array}{r}\text { TECHNICAL QUALITY } \\
\text { Correct Diagnosis } \\
\text { Correct Treatment } \\
\text { ORS } \\
\text { Essential Items Asked } \\
\text { PROVIDER EFFORT } \\
\text { Number of Questions Asked } \\
\text { Length of Visit (minutes) } \\
\text { PATIENT ASSESSMENT } \\
\text { SP Would Return to Doctor } \\
\text { SP Liked Doctor } \\
\text { Global Assessment Index } \\
\text { HARMFUL } \\
\text { Inappropriate Antibiotics }\end{array}$} & 1 & \multirow{15}{*}{$\begin{array}{r}\text { TECHNICAL QUALITY } \\
\text { Correct Diagnosis } \\
\text { Correct Treatment } \\
\text { Essential Items Asked } \\
\text { PROVIDER EFFORT } \\
\text { Number of Questions Asked } \\
\text { Length of Visit (minutes) } \\
\text { PATIENT ASSESSMENT } \\
\text { SP Would Return to Doctor } \\
\text { SP Liked Doctor } \\
\text { Global Assessment Index } \\
\text { HARMFUL } \\
\text { Harmful Treatment }\end{array}$} & 1 & \multirow{13}{*}{$\begin{array}{r}\text { TECHNICAL QUALITY } \\
\text { Correct Diagnosis } \\
\text { Correct Treatment } \\
\text { Essential Items Asked } \\
\text { PROVIDER EFFORT } \\
\text { Number of Questions Asked } \\
\text { Length of Visit (minutes) } \\
\text { PATIENT ASSESSMENT } \\
\text { SP Would Return to Doctor } \\
\text { SP Liked Doctor } \\
\text { Global Assessment Index } \\
\text { HARMFUL } \\
\text { Harmful Treatment }\end{array}$} & \multirow{13}{*}{ 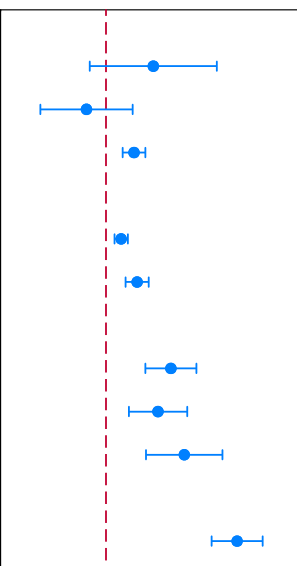 } \\
\hline & $\longmapsto 1$ & & 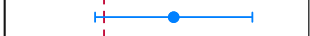 & & \\
\hline & & & $\longmapsto 1$ & & \\
\hline & 4 & & $1 \mapsto-1$ & & \\
\hline & $\left.\right|_{1} ^{1-n}$ & & & & \\
\hline & $i_{101}^{1}$ & & $i_{1}$ & & \\
\hline & 1.er & & $\mapsto-1$ & & \\
\hline & & & & & \\
\hline & $\mapsto-1$ & & 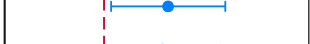 & & \\
\hline & $\longmapsto$ & & & & \\
\hline & $\longmapsto$ & & & & \\
\hline & & & & & \\
\hline & $1 \longmapsto$ & & $\longmapsto$ & & \\
\hline & $\begin{array}{ccccccc}-40 & -20 & 0 & 20 & 40 & 60 & 80 \\
& \text { Doctor Fee (Rupees) }\end{array}$ & & 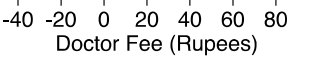 & & $\begin{array}{ccccccc}-40 & -20 & 0 & 20 & 40 & 60 & 80 \\
& \text { Doctor Fee (Rupees) }\end{array}$ \\
\hline & - Estimate $\longmapsto 95 \% \mathrm{CI}$ & & - Estimate $\longmapsto 95 \% \mathrm{Cl}$ & & - Estimate $\longmapsto 95 \% \mathrm{Cl}$ \\
\hline \multicolumn{6}{|c|}{$\begin{array}{l}\text { Each point represents the coefficient from a linear regression with provider fee as the dependent variable and the quality metric indicated on the y-axis as } \\
\text { the explanatory variable, while controlling for provider characteristics (age, sex, years of experience, training, and whether the facility has electricity). } \\
\text { Confidence intervals were estimated using robust standard errors. Panel C pools diarrhea and pneumonia cases. There were no providers that gave the } \\
\text { correct treatment for diarrhea. See appendix tables A2-A7 for complete regression results. } \\
\text { Source: Data comes from standardized patient reports conducted by Mohanan et al. (2015) }\end{array}$} \\
\hline
\end{tabular}




\section{Appendix A. Supplementary Analysis and Extra Data}

\section{Appendix Figures}

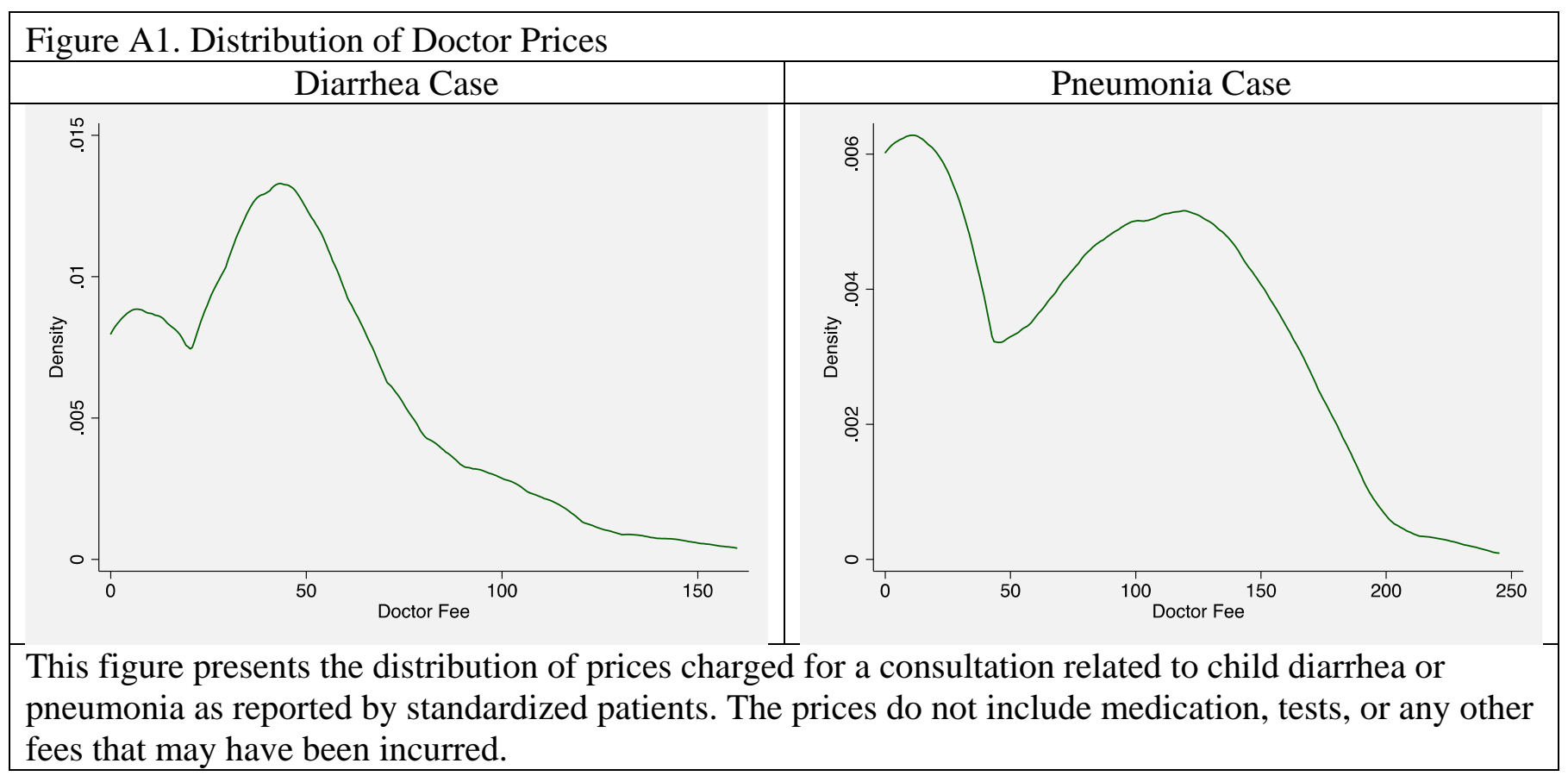




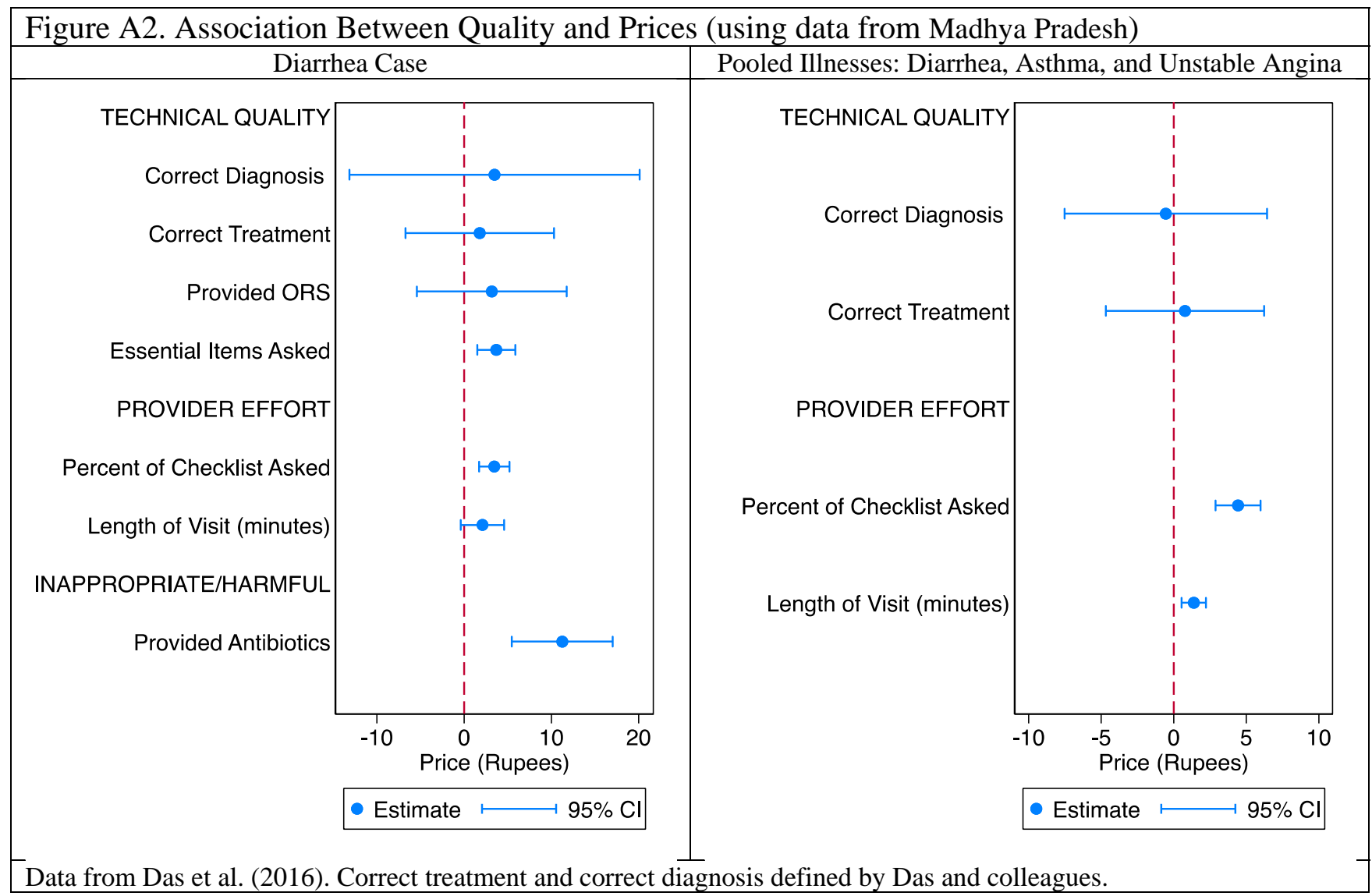




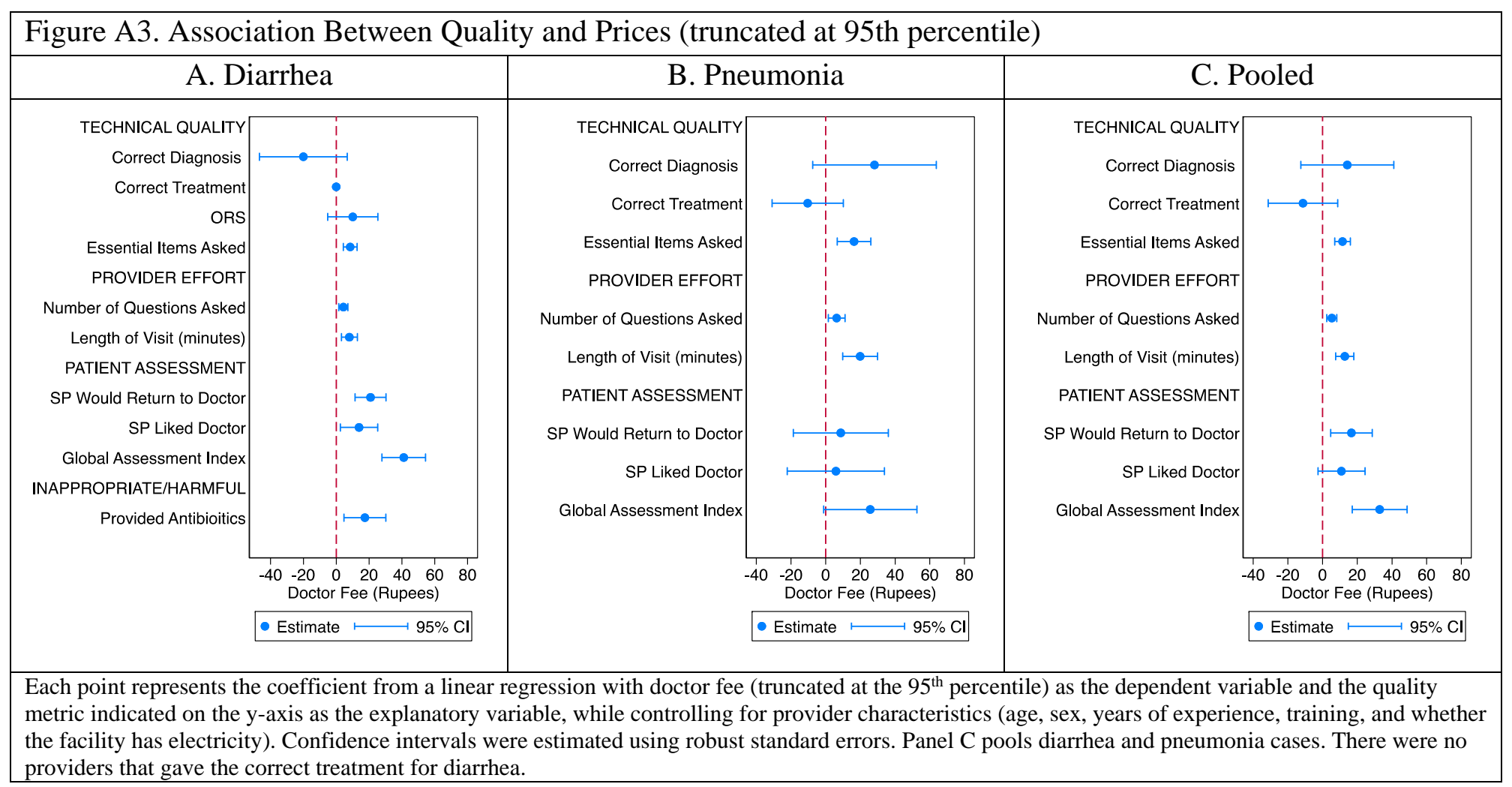




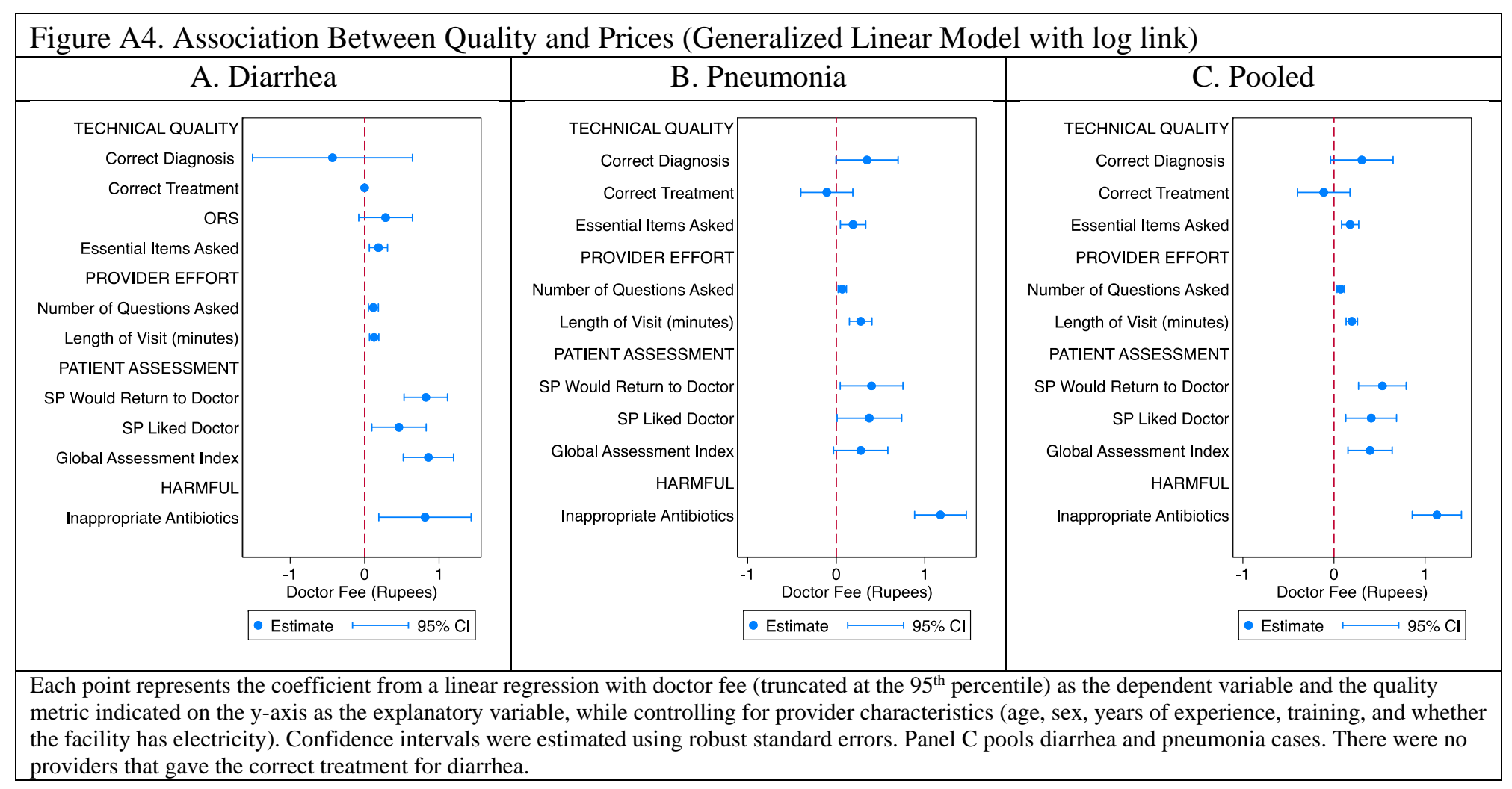




\begin{tabular}{|c|c|c|c|c|c|}
\hline \multicolumn{6}{|c|}{ Figure A5. Association Between Quality and Prices (excluding zero prices) } \\
\hline \multicolumn{2}{|c|}{ A. Diarrhea } & \multicolumn{2}{|c|}{ B. Pneumonia } & \multicolumn{2}{|c|}{ C. Pooled } \\
\hline \multirow{14}{*}{$\begin{array}{r}\text { TECHNICAL QUALITY } \\
\text { Correct Diagnosis } \\
\text { Correct Treatment } \\
\text { ORS } \\
\text { Essential Items Asked } \\
\text { PROVIDER EFFORT } \\
\text { Number of Questions Asked } \\
\text { Length of Visit (minutes) } \\
\text { PATIENT ASSESSMENT } \\
\text { SP Would Return to Doctor } \\
\text { SP Liked Doctor } \\
\text { Global Assessment Index } \\
\text { HARMFUL } \\
\text { Inappropriate Antibiotics }\end{array}$} & 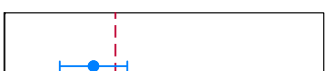 & TECHNICAL QUALITY & & TECHNICAL QUALITY & I \\
\hline & $!$ & Correct Treatment & $\longmapsto$ & Correct Treatment & $\longmapsto$ \\
\hline & $\longmapsto$ & Essential Items Asked & $\stackrel{1}{1} \bullet-1$ & Essential Items Asked & tor \\
\hline & tor & PROVIDER EFFORT & & PROVIDER EFFORT & \\
\hline & & Number of Questions Asked & tor & Number of Questions Asked & tor \\
\hline & 1 & Length of Visit (minutes) & $\bullet$ & Length of Visit (minutes) & $1+0$ \\
\hline & | & PATIENT ASSESSMENT & & PATIENT ASSESSMENT & \\
\hline & $\mapsto$ & SP Would Return to Doctor & & SP Would Return to Doctor & $\mapsto$ \\
\hline & $\longmapsto$ & SP Liked Doctor & $\longmapsto$ & SP Liked Doctor & $\longmapsto$ \\
\hline & $\longmapsto$ & Global Assessment Index & $\longrightarrow$ & Global Assessment Index & $\longmapsto$ \\
\hline & & HARMFUL & & HARMFUL & \\
\hline & $\mapsto$ & Inappropriate Antibiotics & $\longmapsto$ & Inappropriate Antibiotics & $\longmapsto$ \\
\hline & $\begin{array}{ccccccc}-40 & -20 & 0 & 20 & 40 & 60 & 80 \\
& \text { Doctor Fee (Rupees) }\end{array}$ & & $\begin{array}{ccccccc}-40 & -20 & 0 & 20 & 40 & 60 & 80 \\
& \text { Doctor Fee (Rupees) }\end{array}$ & & $\begin{array}{ccccccc}-40 & -20 & 0 & 20 & 40 & 60 & 80 \\
& \text { Doctor Fee (Rupees) }\end{array}$ \\
\hline & - Estimate $\longmapsto 95 \% \mathrm{Cl}$ & & - Estimate $\longmapsto 95 \% \mathrm{Cl}$ & & - Estimate $\longmapsto 95 \% \mathrm{Cl}$ \\
\hline $\begin{array}{l}\text { Each point represents } t \\
\text { metric indicated on the } \\
\text { the facility has electric }\end{array}$ & $\begin{array}{l}\text { the coefficient from a line } \\
\text { e y-axis as the explanatory } \\
\text { ity). Confidence intervals } \\
\text { correct treatment for diar }\end{array}$ & $\begin{array}{l}\text { ression with doctor fee } \\
\text { ble, while controlling } \mathrm{f} \\
\text { estimated using robust }\end{array}$ & $\begin{array}{l}\text { e (truncated at the } 95^{\text {th }} \text { pe } \\
\text { for provider characteristi } \\
\text { t standard errors. Panel C }\end{array}$ & $\begin{array}{l}\text { e) as the dependent va } \\
\text { e, sex, years of experi } \\
\text { s diarrhea and pneumo }\end{array}$ & $\begin{array}{l}\text { ariable and the quality } \\
\text { lence, training, and whethe } \\
\text { onia cases. There were no }\end{array}$ \\
\hline
\end{tabular}




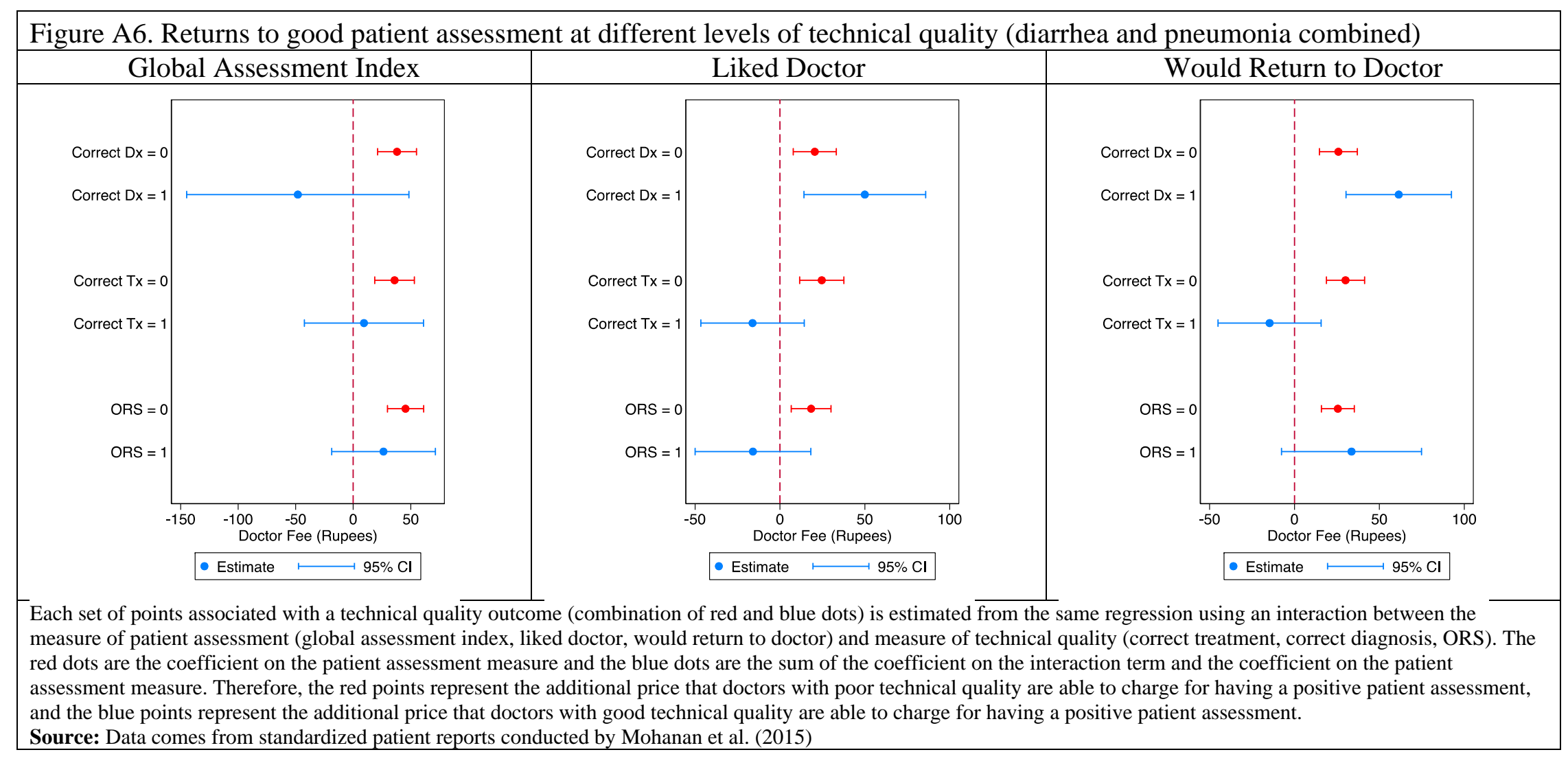




\begin{tabular}{|r|r|r|}
\hline Figure A7. Sensitivity of results to authors' covariate selection \\
\hline A. Coefficient Range & B. P-Value Range \\
\hline TECHNICAL QUALITY \\
Correct Diagnosis \\
Correct Treatment \\
Essential Items Asked \\
PROVIDER EFFORT \\
Number of Questions Asked \\
Length of Visit (minutes) \\
PATIENT ASSESSMENT \\
SP Would Return to Doctor \\
SP Liked Doctor
\end{tabular}




\section{Appendix Tables}

Table A1. Essential Diagnostic Questions

\begin{tabular}{lr}
\hline \hline Questions & \% Asked \\
\hline Diarrhea Cases & \\
Qualities of stool & $58.9 \%$ \\
Frequency & $27.7 \%$ \\
Fever & $8.4 \%$ \\
Vomiting & $24.8 \%$ \\
Taking fluids & $6.4 \%$ \\
Pneumonia Cases & \\
Fever & $68.7 \%$ \\
Breathing is rapid & $34.5 \%$ \\
Difficulty in breathing & $13.3 \%$ \\
\hline \hline
\end{tabular}

For diarrhea cases, we created an index that recorded whether providers asked about 1) the quality of the stool, 2) frequency of stool, 3) whether the child had a fever, 4) whether the child was vomiting, and 5) whether the child was taking fluids (maximum score of 5). For pneumonia cases, our index includes whether the provider asked if the child 1) had a fever, 2) was breathing rapidly, or 3) had difficulty breathing. See appendix table A1 for share of providers that asked each question. 
Table A2. Regression Results for Association Between Technical Quality and Prices for Diarrhea Cases (Figure 1A from Main text)

\begin{tabular}{|c|c|c|c|c|c|}
\hline VARIABLES & $\begin{array}{c}(1) \\
\text { Doctor Fee }\end{array}$ & $\begin{array}{c}(2) \\
\text { Doctor Fee }\end{array}$ & $\begin{array}{c}(3) \\
\text { Doctor Fee }\end{array}$ & $\begin{array}{c}(4) \\
\text { Doctor Fee }\end{array}$ & $\begin{array}{c}(5) \\
\text { Doctor Fee }\end{array}$ \\
\hline Quality Metric & $\begin{array}{c}\text { Correct } \\
\text { Diagnosis }\end{array}$ & $\begin{array}{c}\text { Correct } \\
\text { Treatment }\end{array}$ & ORS & $\begin{array}{c}\text { Essential } \\
\text { Questions }\end{array}$ & Antibiotic \\
\hline Quality & $\begin{array}{l}-13.41 \\
(12.33)\end{array}$ & & $\begin{array}{c}13.14 \\
(8.479)\end{array}$ & $\begin{array}{l}9.35 * * * \\
(2.423)\end{array}$ & $\begin{array}{c}21.95^{* * *} \\
(6.288)\end{array}$ \\
\hline Provider Age & $\begin{array}{l}-0.342 \\
(0.375)\end{array}$ & $\begin{array}{l}-0.316 \\
(0.377)\end{array}$ & $\begin{array}{l}-0.348 \\
(0.379)\end{array}$ & $\begin{array}{l}-0.259 \\
(0.374)\end{array}$ & $\begin{array}{l}-0.338 \\
(0.366)\end{array}$ \\
\hline $\begin{array}{l}\text { Provider is } \\
\text { Male }\end{array}$ & $\begin{array}{c}12.58 \\
(10.80)\end{array}$ & $\begin{array}{c}12.30 \\
(10.56)\end{array}$ & $\begin{array}{c}16.80 * * \\
(6.492)\end{array}$ & $\begin{array}{c}5.215 \\
(9.738)\end{array}$ & $\begin{array}{c}6.132 \\
(5.605)\end{array}$ \\
\hline $\begin{array}{l}\text { Year of } \\
\text { Experience }\end{array}$ & $\begin{array}{c}0.393 \\
(0.391)\end{array}$ & $\begin{array}{c}0.368 \\
(0.393)\end{array}$ & $\begin{array}{c}0.417 \\
(0.392)\end{array}$ & $\begin{array}{c}0.247 \\
(0.381)\end{array}$ & $\begin{array}{c}0.414 \\
(0.392)\end{array}$ \\
\hline $\begin{array}{l}\text { Facility has } \\
\text { Electricity }\end{array}$ & $\begin{array}{c}5.502 \\
(5.329)\end{array}$ & $\begin{array}{c}5.626 \\
(5.330)\end{array}$ & $\begin{array}{c}5.817 \\
(5.328)\end{array}$ & $\begin{array}{c}6.157 \\
(5.117)\end{array}$ & $\begin{array}{c}4.246 \\
(5.244)\end{array}$ \\
\hline $\begin{array}{l}\text { Provider Asked } \\
\text { For Child }\end{array}$ & $\begin{array}{c}-17.99 * * * \\
(6.079)\end{array}$ & $\begin{array}{c}-18.17^{* * *} \\
(6.028)\end{array}$ & $\begin{array}{c}-18.27^{* * *} \\
(6.107)\end{array}$ & $\begin{array}{c}-19.16^{* * *} \\
(5.491)\end{array}$ & $\begin{array}{l}-10.30 * \\
(6.076)\end{array}$ \\
\hline $\begin{array}{l}\text { Provider Has } \\
\text { MBBS Degree }\end{array}$ & $\begin{array}{l}-14.75 \\
(10.66)\end{array}$ & $\begin{array}{c}-18.58 * * \\
(9.397)\end{array}$ & $\begin{array}{c}-19.60 * * \\
(9.786)\end{array}$ & $\begin{array}{c}-19.92 * * \\
(8.524)\end{array}$ & $\begin{array}{l}-14.84 \\
(10.89)\end{array}$ \\
\hline Constant & $\begin{array}{c}50.99 * * * \\
(18.01)\end{array}$ & $\begin{array}{c}50.53^{* * *} \\
(17.90)\end{array}$ & $\begin{array}{c}44.86^{* * *} \\
(15.65)\end{array}$ & $\begin{array}{l}42.23^{* *} \\
(17.38)\end{array}$ & $\begin{array}{c}36.54 * * \\
(14.86)\end{array}$ \\
\hline Observations & 193 & 193 & 193 & 193 & 193 \\
\hline R-squared & 0.129 & 0.125 & 0.141 & 0.195 & 0.167 \\
\hline
\end{tabular}

Robust standard errors in parentheses

*** $\mathrm{p}<0.01, * * \mathrm{p}<0.05, * \mathrm{p}<0.1$ 
Table A3. Regression Results for Association Between Provider Effort/Patient Assessment and Prices for Diarrhea Cases (Fgure 1A from main text)

\begin{tabular}{|c|c|c|c|c|c|}
\hline VARIABLES & $\begin{array}{c}(1) \\
\text { Doctor Fee }\end{array}$ & $\begin{array}{c}(2) \\
\text { Doctor Fee }\end{array}$ & $\begin{array}{c}(3) \\
\text { Doctor Fee }\end{array}$ & $\begin{array}{c}(4) \\
\text { Doctor Fee }\end{array}$ & $\begin{array}{c}(5) \\
\text { Doctor Fee }\end{array}$ \\
\hline Quality Metric & $\begin{array}{c}\text { Number of } \\
\text { Questions } \\
\text { Asked }\end{array}$ & $\begin{array}{l}\text { Length of } \\
\text { Visit }\end{array}$ & $\begin{array}{l}\text { SP Would } \\
\text { Return to } \\
\text { Doctor }\end{array}$ & $\begin{array}{l}\text { SP Liked } \\
\text { Doctor }\end{array}$ & $\begin{array}{c}\text { Global } \\
\text { Assessment } \\
\text { Index } \\
\end{array}$ \\
\hline Quality & $\begin{array}{c}5.630 * * * \\
(1.514)\end{array}$ & $\begin{array}{c}8.191 * * * \\
(2.579)\end{array}$ & $\begin{array}{c}27.06 * * * \\
(4.845)\end{array}$ & $\begin{array}{c}19.15^{* * * *} \\
(5.768)\end{array}$ & $\begin{array}{c}43.92 * * * \\
(7.404)\end{array}$ \\
\hline Provider Age & $\begin{array}{l}-0.179 \\
(0.369)\end{array}$ & $\begin{array}{l}-0.249 \\
(0.370)\end{array}$ & $\begin{array}{l}-0.432 \\
(0.362)\end{array}$ & $\begin{array}{l}-0.259 \\
(0.376)\end{array}$ & $\begin{array}{l}-0.303 \\
(0.352)\end{array}$ \\
\hline $\begin{array}{l}\text { Provider is } \\
\text { Male }\end{array}$ & $\begin{array}{c}5.121 \\
(10.84)\end{array}$ & $\begin{array}{c}24.83 * * * \\
(8.401)\end{array}$ & $\begin{array}{c}5.896 \\
(18.88)\end{array}$ & $\begin{array}{c}5.953 \\
(16.02)\end{array}$ & $\begin{array}{c}7.939 \\
(16.17)\end{array}$ \\
\hline $\begin{array}{l}\text { Year of } \\
\text { Experience }\end{array}$ & $\begin{array}{c}0.220 \\
(0.368)\end{array}$ & $\begin{array}{c}0.202 \\
(0.371)\end{array}$ & $\begin{array}{c}0.429 \\
(0.353)\end{array}$ & $\begin{array}{c}0.247 \\
(0.382)\end{array}$ & $\begin{array}{c}0.207 \\
(0.347)\end{array}$ \\
\hline $\begin{array}{l}\text { Facility has } \\
\text { Electricity }\end{array}$ & $\begin{array}{c}7.161 \\
(5.218)\end{array}$ & $\begin{array}{c}4.957 \\
(5.273)\end{array}$ & $\begin{array}{c}5.012 \\
(4.941)\end{array}$ & $\begin{array}{c}5.107 \\
(5.180)\end{array}$ & $\begin{array}{c}4.425 \\
(4.930)\end{array}$ \\
\hline $\begin{array}{l}\text { Provider Asked } \\
\text { For Child }\end{array}$ & $\begin{array}{c}-20.51^{* * *} \\
(5.599)\end{array}$ & $\begin{array}{c}-18.28 * * * \\
(5.916)\end{array}$ & $\begin{array}{c}-19.98 * * * \\
(5.649)\end{array}$ & $\begin{array}{c}-19.26 * * * \\
(5.747)\end{array}$ & $\begin{array}{c}-18.63 * * * \\
(5.433)\end{array}$ \\
\hline $\begin{array}{l}\text { Provider Has } \\
\text { MBBS Degree }\end{array}$ & $\begin{array}{l}-18.08 * \\
(9.430)\end{array}$ & $\begin{array}{l}-14.91 \\
(9.380)\end{array}$ & $\begin{array}{l}-18.05 * \\
(10.11)\end{array}$ & $\begin{array}{c}-17.54^{* *} \\
(8.760)\end{array}$ & $\begin{array}{l}-13.83 \\
(9.718)\end{array}$ \\
\hline Constant & $\begin{array}{c}37.77 * * \\
(17.82)\end{array}$ & $\begin{array}{c}22.64 \\
(16.56)\end{array}$ & $\begin{array}{l}39.26 * \\
(23.20)\end{array}$ & $\begin{array}{l}39.66^{*} \\
(21.43)\end{array}$ & $\begin{array}{l}-17.19 \\
(23.04)\end{array}$ \\
\hline Observations & 193 & 193 & 193 & 193 & 192 \\
\hline R-squared & 0.196 & 0.169 & 0.244 & 0.171 & 0.255 \\
\hline
\end{tabular}

Robust standard errors in parentheses

$* * * \mathrm{p}<0.01, * * \mathrm{p}<0.05, * \mathrm{p}<0.1$ 
Table A4. Regression Results for Association Between Technical Quality and Prices for Pneumonia Cases (Figure 1B from main text)

\begin{tabular}{|c|c|c|c|c|c|}
\hline VARIABLES & $\begin{array}{c}(1) \\
\text { Doctor Fee }\end{array}$ & $\begin{array}{c}(2) \\
\text { Doctor Fee }\end{array}$ & $\begin{array}{c}(3) \\
\text { Doctor Fee }\end{array}$ & $\begin{array}{c}(4) \\
\text { Doctor Fee }\end{array}$ & $\begin{array}{c}(5) \\
\text { Doctor Fee }\end{array}$ \\
\hline Quality Metric & $\begin{array}{c}\text { Correct } \\
\text { Diagnosis } \\
\end{array}$ & $\begin{array}{c}\text { Correct } \\
\text { Treatment }\end{array}$ & $\begin{array}{c}\text { Essential } \\
\text { Questions }\end{array}$ & Antibiotic & $\begin{array}{c}\text { Inappropriate } \\
\text { Antibiotic } \\
\end{array}$ \\
\hline Quality & $\begin{array}{l}32.45^{*} \\
(18.70)\end{array}$ & $\begin{array}{l}-7.728 \\
(10.48)\end{array}$ & $\begin{array}{c}16.59 * * * \\
(5.154)\end{array}$ & $\begin{array}{c}79.37 * * * \\
(6.713)\end{array}$ & $\begin{array}{c}74.81^{* * *} \\
(7.320)\end{array}$ \\
\hline Provider Age & $\begin{array}{l}-0.380 \\
(0.519)\end{array}$ & $\begin{array}{l}-0.175 \\
(0.552)\end{array}$ & $\begin{array}{l}-0.388 \\
(0.564)\end{array}$ & $\begin{array}{l}0.0383 \\
(0.366)\end{array}$ & $\begin{array}{l}0.0789 \\
(0.392)\end{array}$ \\
\hline Provider is Male & $\begin{array}{c}42.98 \\
(28.64)\end{array}$ & $\begin{array}{c}26.65 \\
(38.08)\end{array}$ & $\begin{array}{c}23.08 \\
(29.67)\end{array}$ & $\begin{array}{c}4.597 \\
(11.73)\end{array}$ & $\begin{array}{c}19.68 \\
(14.36)\end{array}$ \\
\hline $\begin{array}{l}\text { Year of } \\
\text { Experience }\end{array}$ & $\begin{array}{c}0.0997 \\
(0.623)\end{array}$ & $\begin{array}{l}-0.0725 \\
(0.648)\end{array}$ & $\begin{array}{l}-0.0532 \\
(0.645)\end{array}$ & $\begin{array}{l}-0.333 \\
(0.428)\end{array}$ & $\begin{array}{l}0.0289 \\
(0.409)\end{array}$ \\
\hline $\begin{array}{l}\text { Facility has } \\
\text { Electricity }\end{array}$ & $\begin{array}{c}0.533 \\
(9.797)\end{array}$ & $\begin{array}{l}-0.924 \\
(9.954)\end{array}$ & $\begin{array}{c}4.804 \\
(9.752)\end{array}$ & $\begin{array}{c}1.318 \\
(8.265)\end{array}$ & $\begin{array}{c}5.147 \\
(8.089)\end{array}$ \\
\hline $\begin{array}{l}\text { Provider Asked } \\
\text { For Child }\end{array}$ & $\begin{array}{l}-16.89 * \\
(9.692)\end{array}$ & $\begin{array}{l}-15.76 \\
(9.695)\end{array}$ & $\begin{array}{l}-10.31 \\
(9.574)\end{array}$ & $\begin{array}{l}-6.433 \\
(7.880)\end{array}$ & $\begin{array}{l}-9.223 \\
(7.690)\end{array}$ \\
\hline $\begin{array}{l}\text { Provider Has } \\
\text { MBBS Degree }\end{array}$ & $\begin{array}{l}-26.20 \\
(31.69)\end{array}$ & $\begin{array}{l}-26.00 \\
(30.59)\end{array}$ & $\begin{array}{l}-18.69 \\
(28.17)\end{array}$ & $\begin{array}{c}1.164 \\
(15.83)\end{array}$ & $\begin{array}{l}-13.11 \\
(15.72)\end{array}$ \\
\hline Constant & $\begin{array}{c}45.34 \\
(35.18)\end{array}$ & $\begin{array}{c}65.54 \\
(42.91)\end{array}$ & $\begin{array}{c}48.69 \\
(35.76)\end{array}$ & $\begin{array}{c}26.74 \\
(19.31)\end{array}$ & $\begin{array}{c}12.45 \\
(22.19)\end{array}$ \\
\hline Observations & 186 & 186 & 185 & 186 & 186 \\
\hline R-squared & 0.125 & 0.129 & 0.101 & 0.409 & 0.407 \\
\hline
\end{tabular}

Robust standard errors in parentheses

*** $\mathrm{p}<0.01, * * \mathrm{p}<0.05, * \mathrm{p}<0.1$ 
Table A5. Regression Results for Association Between Provider Effort/Patient Assessment and Prices for Pneumonia Cases (Figure 1B from Main text)

\begin{tabular}{lccccc}
\hline \hline & $(1)$ & $(2)$ & $(3)$ & $(4)$ & $(5)$ \\
VARIABLES & Doctor Fee & Doctor Fee & Doctor Fee & Doctor Fee & Doctor Fee \\
\hline Quality Metric & $\begin{array}{c}\text { Number of } \\
\text { Questions } \\
\text { Asked }\end{array}$ & $\begin{array}{c}\text { Length of } \\
\text { Visit }\end{array}$ & $\begin{array}{c}\text { SP Would } \\
\text { Return to } \\
\text { Doctor }\end{array}$ & $\begin{array}{c}\text { SP Liked } \\
\text { Doctor }\end{array}$ & $\begin{array}{c}\text { Global } \\
\text { Assessment } \\
\text { Index }\end{array}$ \\
\hline Quality & $7.335^{* * *}$ & $21.23^{* * *}$ & $29.80^{* *}$ & $27.18^{* *}$ & $25.18^{*}$ \\
Provider Age & $(2.417)$ & $(4.973)$ & $(13.55)$ & $(13.76)$ & $(14.17)$ \\
Provider is & -0.246 & -0.0395 & -0.262 & -0.282 & -0.218 \\
Male & $(0.549)$ & $(0.554)$ & $(0.533)$ & $(0.539)$ & $(0.537)$ \\
Year of & 8.991 & 0.864 & 20.08 & 20.35 & $-28.07 * *$ \\
Experience & $(35.35)$ & $(29.81)$ & $(31.28)$ & $(31.85)$ & $(11.23)$ \\
Facility has & -0.123 & -0.121 & -0.0595 & -0.0791 & -0.103 \\
Electricity & $(0.627)$ & $(0.649)$ & $(0.631)$ & $(0.641)$ & $(0.631)$ \\
Provider Asked & 3.900 & 0.318 & 2.333 & 1.895 & 2.114 \\
For Child & $(9.823)$ & $(9.595)$ & $(9.883)$ & $(9.881)$ & $(9.989)$ \\
Provider Has & -13.10 & -10.57 & $-21.24 * *$ & $-20.10 * *$ & $-17.55^{*}$ \\
MBBS Degree & $(9.336)$ & $(9.590)$ & $(10.14)$ & $(10.09)$ & $(9.827)$ \\
Constant & -18.23 & -8.894 & -29.34 & -27.85 & -22.38 \\
Observations & $(31.08)$ & $(29.58)$ & $(31.17)$ & $(31.31)$ & $(31.24)$ \\
R-squared & 48.60 & 43.33 & 59.19 & 60.47 & $70.00^{*}$ \\
\hline Robust & $(40.35)$ & $(34.90)$ & $(36.90)$ & $(37.55)$ & $(35.77)$ \\
& 186 & 186 & 186 & 186 & 185 \\
& 0.106 & 0.124 & 0.080 & 0.074 & 0.072 \\
\hline
\end{tabular}

Robust standard errors in parentheses

$* * * \mathrm{p}<0.01, * * \mathrm{p}<0.05, * \mathrm{p}<0.1$ 
Table A6. Regression Results for Association Between Technical Quality and Prices for Illnesses Pooled (Figure 1C from main text)

\begin{tabular}{|c|c|c|c|c|}
\hline VARIABLES & $\begin{array}{c}(1) \\
\text { Doctor Fee }\end{array}$ & $\begin{array}{c}(2) \\
\text { Doctor Fee } \\
\end{array}$ & $\begin{array}{c}(3) \\
\text { Doctor Fee }\end{array}$ & $\begin{array}{c}(5) \\
\text { Doctor Fee }\end{array}$ \\
\hline Quality Metric & $\begin{array}{c}\text { Correct } \\
\text { Diagnosis }\end{array}$ & $\begin{array}{c}\text { Correct } \\
\text { Treatment }\end{array}$ & $\begin{array}{c}\text { Essential } \\
\text { Questions }\end{array}$ & $\begin{array}{c}\text { Inappropriate } \\
\text { Antibiotic }\end{array}$ \\
\hline Quality & $\begin{array}{c}20.43 \\
(14.02)\end{array}$ & $\begin{array}{l}-8.475 \\
(10.20)\end{array}$ & $\begin{array}{c}12.08 * * * \\
(2.491)\end{array}$ & $\begin{array}{c}56.65^{* * *} \\
(5.613)\end{array}$ \\
\hline Provider Age & $\begin{array}{l}-0.271 \\
(0.335)\end{array}$ & $\begin{array}{l}-0.223 \\
(0.350)\end{array}$ & $\begin{array}{l}-0.269 \\
(0.350)\end{array}$ & $\begin{array}{l}-0.153 \\
(0.277)\end{array}$ \\
\hline Provider is Male & $\begin{array}{c}24.57 \\
(17.83)\end{array}$ & $\begin{array}{c}20.44 \\
(20.11)\end{array}$ & $\begin{array}{c}14.50 \\
(17.66)\end{array}$ & $\begin{array}{c}7.932 \\
(12.01)\end{array}$ \\
\hline Year of Experience & $\begin{array}{c}0.155 \\
(0.379)\end{array}$ & $\begin{array}{c}0.126 \\
(0.390)\end{array}$ & $\begin{array}{l}0.0506 \\
(0.384)\end{array}$ & $\begin{array}{c}0.215 \\
(0.304)\end{array}$ \\
\hline $\begin{array}{l}\text { Facility has } \\
\text { Electricity }\end{array}$ & $\begin{array}{c}2.873 \\
(5.403)\end{array}$ & $\begin{array}{c}2.382 \\
(5.469)\end{array}$ & $\begin{array}{c}4.563 \\
(5.294)\end{array}$ & $\begin{array}{c}2.971 \\
(4.816)\end{array}$ \\
\hline $\begin{array}{l}\text { Provider Asked For } \\
\text { Child }\end{array}$ & $\begin{array}{c}-16.75^{* * *} \\
(6.161)\end{array}$ & $\begin{array}{c}-16.30^{* * *} \\
(6.186)\end{array}$ & $\begin{array}{c}-14.49 * * \\
(5.969)\end{array}$ & $\begin{array}{l}-5.291 \\
(5.430)\end{array}$ \\
\hline $\begin{array}{l}\text { Provider Has } \\
\text { MBBS Degree }\end{array}$ & $\begin{array}{l}-24.83 * \\
(13.95)\end{array}$ & $\begin{array}{l}-21.31 * \\
(12.74)\end{array}$ & $\begin{array}{l}-20.49 * \\
(11.72)\end{array}$ & $\begin{array}{l}-10.99 \\
(11.65)\end{array}$ \\
\hline Constant & $\begin{array}{l}59.69 * * \\
(24.18)\end{array}$ & $\begin{array}{c}68.44 * * * \\
(25.74)\end{array}$ & $\begin{array}{l}58.47 * * \\
(23.58)\end{array}$ & $\begin{array}{l}40.55 * * \\
(18.04)\end{array}$ \\
\hline Observations & 379 & 379 & 378 & 379 \\
\hline R-squared & 0.156 & 0.149 & 0.194 & 0.358 \\
\hline
\end{tabular}

Robust standard errors in parentheses

*** $\mathrm{p}<0.01,{ }^{* *} \mathrm{p}<0.05,{ }^{*} \mathrm{p}<0.1$ 
Table A7. Regression Results for Association Between Provider Effort/Patient Assessment and Prices for Illnesses Pooled (Figure 1C from Main text)

\begin{tabular}{|c|c|c|c|c|c|}
\hline VARIABLES & $\begin{array}{c}(1) \\
\text { Doctor Fee }\end{array}$ & $\begin{array}{c}(2) \\
\text { Doctor Fee }\end{array}$ & $\begin{array}{c}(3) \\
\text { Doctor Fee }\end{array}$ & $\begin{array}{c}(4) \\
\text { Doctor Fee }\end{array}$ & $\begin{array}{c}(5) \\
\text { Doctor Fee }\end{array}$ \\
\hline Quality Metric & $\begin{array}{c}\text { Number of } \\
\text { Questions } \\
\text { Asked }\end{array}$ & $\begin{array}{l}\text { Length of } \\
\text { Visit }\end{array}$ & $\begin{array}{l}\text { SP Would } \\
\text { Return to } \\
\text { Doctor }\end{array}$ & $\begin{array}{l}\text { SP Liked } \\
\text { Doctor }\end{array}$ & $\begin{array}{c}\text { Global } \\
\text { Assessment } \\
\text { Index }\end{array}$ \\
\hline Quality & $\begin{array}{c}6.529 * * * \\
(1.475)\end{array}$ & $\begin{array}{c}13.43 * * * \\
(2.547)\end{array}$ & $\begin{array}{c}28.03 * * * \\
(5.633)\end{array}$ & $\begin{array}{c}22.45 * * * \\
(6.422)\end{array}$ & $\begin{array}{c}33.82 * * * \\
(8.426)\end{array}$ \\
\hline Provider Age & $\begin{array}{l}-0.185 \\
(0.346)\end{array}$ & $\begin{array}{l}-0.144 \\
(0.346)\end{array}$ & $\begin{array}{l}-0.328 \\
(0.338)\end{array}$ & $\begin{array}{l}-0.251 \\
(0.346)\end{array}$ & $\begin{array}{l}-0.279 \\
(0.335)\end{array}$ \\
\hline $\begin{array}{l}\text { Provider is } \\
\text { Male }\end{array}$ & $\begin{array}{c}8.527 \\
(18.90)\end{array}$ & $\begin{array}{c}22.53 \\
(17.18)\end{array}$ & $\begin{array}{c}13.62 \\
(18.92)\end{array}$ & $\begin{array}{c}13.34 \\
(18.97)\end{array}$ & $\begin{array}{l}-3.185 \\
(15.11)\end{array}$ \\
\hline $\begin{array}{l}\text { Year of } \\
\text { Experience }\end{array}$ & $\begin{array}{l}0.0230 \\
(0.376)\end{array}$ & $\begin{array}{l}-0.0146 \\
(0.384)\end{array}$ & $\begin{array}{c}0.165 \\
(0.374)\end{array}$ & $\begin{array}{l}0.0636 \\
(0.387)\end{array}$ & $\begin{array}{l}0.0759 \\
(0.374)\end{array}$ \\
\hline $\begin{array}{l}\text { Facility has } \\
\text { Electricity }\end{array}$ & $\begin{array}{c}5.252 \\
(5.342)\end{array}$ & $\begin{array}{c}2.052 \\
(5.342)\end{array}$ & $\begin{array}{c}3.548 \\
(5.282)\end{array}$ & $\begin{array}{c}3.213 \\
(5.357)\end{array}$ & $\begin{array}{c}3.980 \\
(5.328)\end{array}$ \\
\hline $\begin{array}{l}\text { Provider Asked } \\
\text { For Child }\end{array}$ & $\begin{array}{c}-16.15^{* * *} \\
(5.916)\end{array}$ & $\begin{array}{c}-14.76^{* *} \\
(6.025)\end{array}$ & $\begin{array}{c}-20.22 * * * \\
(6.149)\end{array}$ & $\begin{array}{c}-19.02 * * * \\
(6.156)\end{array}$ & $\begin{array}{c}-18.36 * * * \\
(6.179)\end{array}$ \\
\hline $\begin{array}{l}\text { Provider Has } \\
\text { MBBS Degree }\end{array}$ & $\begin{array}{l}-18.43 \\
(12.74)\end{array}$ & $\begin{array}{l}-13.33 \\
(12.58)\end{array}$ & $\begin{array}{l}-21.95 * \\
(13.17)\end{array}$ & $\begin{array}{l}-20.98 \\
(12.79)\end{array}$ & $\begin{array}{l}-17.21 \\
(13.17)\end{array}$ \\
\hline Constant & $\begin{array}{l}48.07^{*} \\
(24.99)\end{array}$ & $\begin{array}{l}39.30 * \\
(23.58)\end{array}$ & $\begin{array}{c}64.34 * * * \\
(24.49)\end{array}$ & $\begin{array}{c}64.94 * * * \\
(24.67)\end{array}$ & $\begin{array}{c}26.42 \\
(26.89)\end{array}$ \\
\hline Observations & 379 & 379 & 379 & 379 & 377 \\
\hline R-squared & 0.199 & 0.196 & 0.194 & 0.172 & 0.189 \\
\hline
\end{tabular}

Robust standard errors in parentheses

*** $\mathrm{p}<0.01, * * \mathrm{p}<0.05, * \mathrm{p}<0.1$ 
Table A8. Association between patient assessment and technical quality

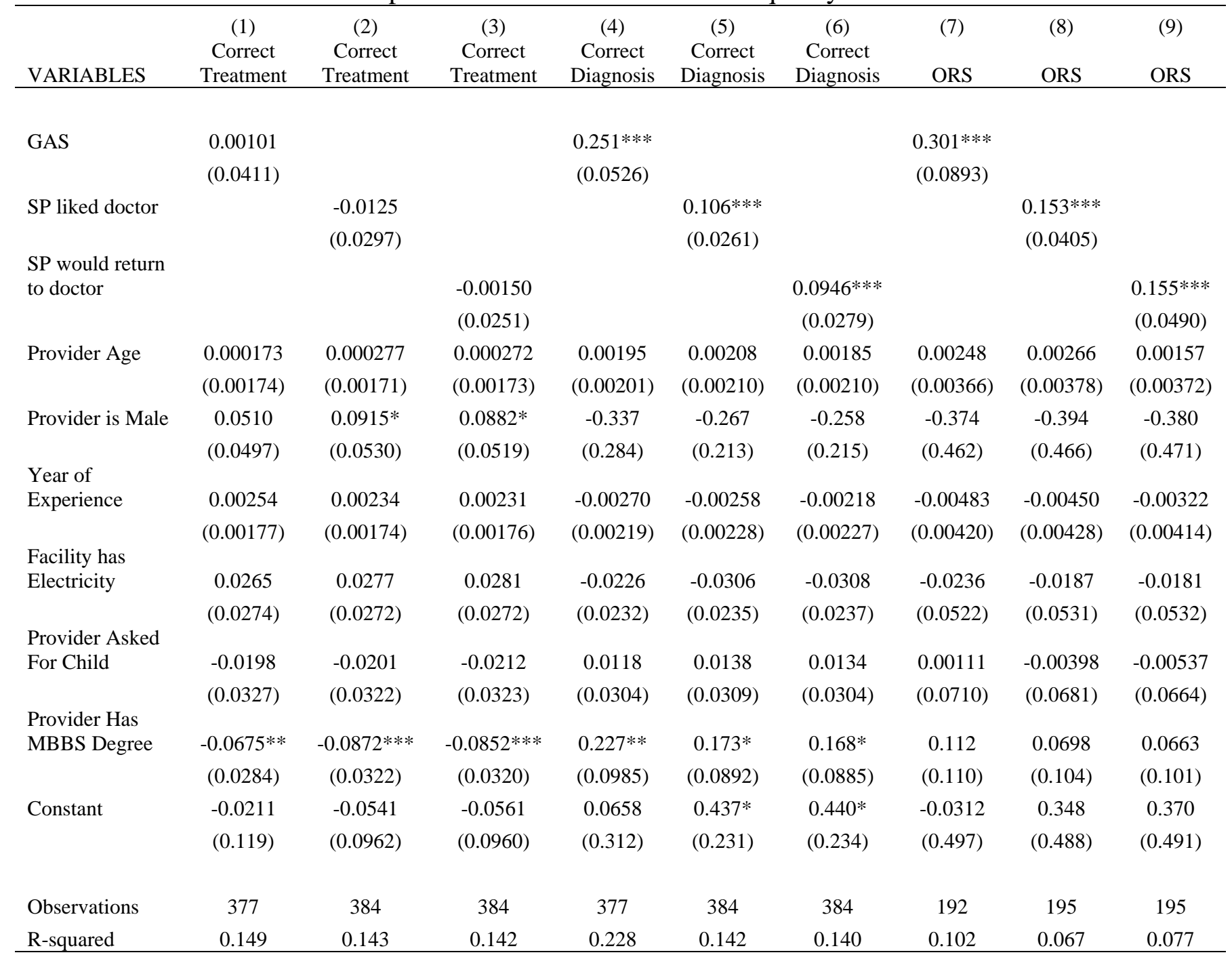

Robust standard errors in parentheses

$* * * \mathrm{p}<0.01, * * \mathrm{p}<0.05,{ }^{*} \mathrm{p}<0.1$ 
Table A9. Regression results for DCE (figure 3 from main text)

(1)

VARIABLES

$\operatorname{Pr}$ (doctor chosen)

Price $($ reference $=$ free $)$

100 INR

$0.177 * * *$

(0.0256)

200 INR

$0.0994 * * *$

(0.0337)

300 INR

$0.0868 * *$

(0.0380)

Quality (reference $=$ 1-star)

3-stars

$0.339 * * *$

(0.0237)

5-stars

$0.643 * * *$

(0.0214)

Time to arrive at facility (reference $=60$ mins)

30 mins

$0.0587 * *$

(0.0286)

20 mins

$0.0788 * *$

(0.0313)

10 mins

$0.0934 * * *$

(0.0274)

Degree (reference $=$ no degree)

Ayurvedic

$0.494^{* * *}$

(0.0242)

Homeopathic

$0.482 * * *$

(0.0291)

MBBS/MD

$0.792 * * *$

(0.0312)

Constant

$-0.395^{* * *}$

(0.0305)

Observations

8,032

R-squared

0.288

Choice set fixed-effects

Yes

Standard errors in parentheses are clustered by respondent ID *** $\mathrm{p}<0.01,{ }^{* *} \mathrm{p}<0.05,{ }^{*} \mathrm{p}<0.1$ 
Table A10. Provider Characteristics

\begin{tabular}{lcc}
\hline \hline & \multicolumn{2}{c}{ Illness presented by } \\
& $\begin{array}{c}\text { Standardized Patient } \\
\text { Diarrhea }\end{array}$ & $\begin{array}{c}\text { Pneumonia } \\
(\mathrm{N}=205)\end{array}$ \\
\hline Age & 42.88 & 44.51 \\
Male & $(10.48)$ & $(11.21)$ \\
& 0.99 & 0.99 \\
Experience (Years) & $(0.1)$ & $(0.1)$ \\
MBBS Degree & 16.68 & 18.3 \\
No Training & $(10.01)$ & $(10.55)$ \\
Electricity in Facility & 0.06 & 0.04 \\
Age of Facility & $(0.24)$ & $(0.2)$ \\
Number of Consulting Rooms & 0.71 & 0.75 \\
& $(0.46)$ & $(0.43)$ \\
& 0.65 & 0.69 \\
\hline \hline
\end{tabular}

Source: Data comes from a provider survey of all providers who received a visit from a standardized patient and was carried out by Mohanan et al. (2015). 
Table A11. DCE Respondent Characteristics

\begin{tabular}{|c|c|}
\hline & $\begin{array}{c}\text { Mean } \\
(\mathrm{SD})\end{array}$ \\
\hline \multirow[t]{2}{*}{ Age of Youngest Child } & 3.59 \\
\hline & $(2.62)$ \\
\hline \multirow[t]{2}{*}{ Respondent Male } & 0.16 \\
\hline & $(0.37)$ \\
\hline \multirow[t]{2}{*}{ Respondent Age } & 29.46 \\
\hline & $(7.95)$ \\
\hline \multirow[t]{2}{*}{ Any Education } & 0.73 \\
\hline & $(0.44)$ \\
\hline \multirow[t]{2}{*}{ No Religion } & 0.02 \\
\hline & $(0.04)$ \\
\hline \multirow[t]{2}{*}{ Hindu } & 0.88 \\
\hline & $(0.33)$ \\
\hline \multirow[t]{2}{*}{ Muslim } & 0.12 \\
\hline & $(0.33)$ \\
\hline \multirow[t]{2}{*}{ Christian } & 0.01 \\
\hline & $(0.03)$ \\
\hline \multirow[t]{2}{*}{ Number of Children } & 1.89 \\
\hline & $(0.99)$ \\
\hline \multirow[t]{2}{*}{ Child had diarrhea in 4 weeks } & 0.13 \\
\hline & $(0.34)$ \\
\hline \multirow[t]{2}{*}{ Sought Treatment } & 0.91 \\
\hline & $(0.28)$ \\
\hline \multirow[t]{2}{*}{ Doctor fee (rupees) } & 216.29 \\
\hline & $(250.86)$ \\
\hline \multirow[t]{2}{*}{ Time to arrive at facility (Mins) } & 17.93 \\
\hline & (17.69) \\
\hline \multirow[t]{2}{*}{ Satisfaction } & 0.87 \\
\hline & $(0.33)$ \\
\hline \multirow[t]{2}{*}{ Below Poverty Line } & 0.58 \\
\hline & $(0.49)$ \\
\hline
\end{tabular}

Means are based on 500 caretakers of children under 10 years of age

Source: Survey carried out by authors 


\section{Appendix B: Additional Information On Standardized Patient Methods}

\section{Validity and Benefits of SP Method}

The SP method is an established and valid method for practitioner performance measurement because it presents a well-defined incognito case in a clinically accurate and consistent manner to all practitioners.(Das et al., 2012, Rethans et al., 1991, Rethans et al., 2007)This method has several benefits. First, it ensures illness and patient characteristics are identical across providers, which limits concerns about differential patient sorting across clinics, as might be the case when observing real patient-provider interactions. Second, because we know the actual illness being presented and the optimal care associated with the case, we can objectively score the quality of care provided. Third, we are able to observe prices charged for completed transactions, which is more accurate than prices self-reported by providers. Finally, there are no concerns about Hawthorne effects because providers are unaware that the visit is being studied.

\section{Global Assessment Index}

SPs rated the provider on several characteristics associated with the visit on 1-4 scales: 1) Did the provider create an environment in which you could convey your symptoms and concerns easily? 2) Did the provider appear to be knowledgeable about your illness? 3) Did the provider address your worries seriously? 4) Did the provider explain anything about your illness?

\section{Provider Sampling}

Among 360 clusters in the study area for the Bihar Evaluation of Social Franchising and Telemedicine (BEST)(Mohanan, et al., 2015), 80 were selected at random. Study clusters were defined as sets of villages surrounding a central village that met eligibility criteria for a telemedicine center - the primary criteria being the availability of Internet connectivity and potential franchisees, with infrastructure such as dedicated space. The BEST team generated a list of all health care practitioners visited in the past 6 months - regardless of medical qualifications - from interviews with 64 randomly selected households with children younger than 5 years per cluster. The 5 most frequently visited primary health care practitioners in each cluster were included in the study.

\section{Roles for Standardized Patients}

\section{Diarrhea Case}

Sangeeta said to her husband Santosh "get some medicines for Sonu, he has loose-motions, if we take him now, he'll soil his clothes”. Sonu is suffering from loose-motions since the night before last. Yesterday night he went to pass stool 8-9 times and he has been crying too. Now that he has fallen asleep Sangeeta is thinking about getting all household work done quickly.

Santosh his wife and child stay together with his parents in a nearby village. Santosh is a 25 year old cheerful person, he has been educated till class 8 . He works as a helper on a vehicle and rears cattle and earns about 2500-3000 rupees per month. He spends most of his time outside for work; he is at home from last 4 days. Sangeeta keeps the house clean but she feels that the neighborhood is not clean. They drink water from a handpump and they keep the drinking water covered but they don't boil it. 
Their son Sonu is 2 years old and all his teeth have come out. He is active all day; he is growing fine and is talkative. Sonu plays in the mud but does not eat mud; he has been vaccinated when he was an infant. Sangeeta has not seen any worms in his stool. He is not suffering from any other illness. He stopped breastfeeding just 6 months back and eats whatever is cooked in the house, though he likes to eat biscuits.

Sonu has been suffering from loose-motions since the night before last, the stool id not foamy or greasy, it does not smell foul. Sonu is crying a lot, it seems as if he has recurring pain in his stomach. There has been no vomit.

There has been no change in the food habits of Sonu, Sangeeta is feeding Sonu porridge and milk from a bottle, she cleans the bottle with warm water after feeding Sonu from it. Sonu is drinking lots of water. Santosh does not feel that his child is weak, irritated or tired. Sonu's body is not warm on touching.

For the last two days, the child has had a diarrhea, and he has been suffering from pain in the stomach occasionally bot not all the time, and the stomach is not swollen. The diarrhea is watery, yellow, does not have mucous (chiknahat, balgam or jhag) or blood in it (the doctor may ask these questions to rule out dysentery from viral diarrhea). In addition it is not particularly foul smelling and is not, what is called 'explosive diarrhea' (the doctor may ask this to rule out giardia or other infestations). The father does not think that the child has any fever; he has not given any medicines to the child; he has given the child water to drink, but not with any salt or sugar in it.

\section{Pneumonia Case}

Rita, told her husband Baliram to go and get medicine for their son Munna, as he could not sleep well last night because he was having difficulty breathing. He has fever and cough since last five days, which is not getting better and since last night is also having difficulty breathing.

Baliram Yadav is a 24 years old who has studied upto 8th standard. He lives with his family in a two room pucca house in the village and his family comprises of his wife, son and his parents. He works as a helper with a truck driver and from it earns rupees 4000 a month. Due to his work he stays away from home most of the time but is home since last four days.

Rita is a housewife and most of her time is spent cooking food on chulha and rearing cattle. The house she lives in does not have a toilet thus she and her family uses a nearby pit toilet in the village. She keeps her house neat and clean but feels her neighborhood is dirty. She draws drinking water for the family from a handpump and stores it in an earthen pot, which she covers but does not boil the water.

Munna their son, is two years old and during his birth weigh $2.4 \mathrm{kgs}$. He has all his milk teeth and generally keeps well. But he has not got all the immmunisation vaccine shots. Munna does not suffer from any allergies and neither does he get any epilepsy attack.

Baliram and Rita are worried about Munna and thus when Munna had fever they consulted a village doctor who gave them some Desi medicine for it. They do not know the name of the medicine the provider gave but munna's condition did not improve upon taking the medicine. He has got weak and is not playing much and keeps lying down most of the time. He is sleeping more than usual and is lazy. He eats normal food cooked at home and was weaned away from breastfeeding a year ago. But he loves eating buiscuits. And recently he has not eaten any cold 
thing. Baliram has heard of a good doctor in a nearby village whose treatment is very good and thus he has come to this doctor to get medicine for Munna.

The child has been suffering from high fever for five days and is burning to touch. He has continuous cough which is similar in day and night. There was no blood in the cough but there was vomiting after coughing since yesterday. The child is spitting out only mucous and saliva but no phlegm. He has been breathing rapidly and his nostrils appear to be flaring when he breathes. Also, the skin between his ribs and stomach and also the neck muscles seems to be straining when he breathes. He makes a harsh sound since he started having difficulty breathing. The father tried to keep the child warm by covering him with the blanket last night when he started having this breathing difficulty. He does not have a running or blocked nose. He does not have any stomach ache but had loose motions a couple of times in the last two days. He has chest pain and also complained of head ache but no ear pain. There was been a decrease in frequency of urination and the child does not have any tears while crying. Also, the colour of the fingernails of the child has become more dark than normal. 


\section{Appendix C: Discrete Choice Experiment}

\section{Sampling for DCE}

We used the 2011 Indian census to construct a sample frame of Patna, a smaller urban center in Bihar State. A geographically representative sampling strategy was used for this study. The urban wards of the city were divided into five geographical regions and 10 random starting points were selected in each region with 50 total starting points. Every 4th household from the starting point was visited until 20 interviews from each starting point were completed. Several households contacted were ineligible for the survey or refused to consent to participate in the interview. Respondents were adults over 18 years of age who were decision makers or caregivers for a child under 10 years of age in the household. Overall, 500 interviews were completed. $48.5 \%$ of households contacted were eligible for the survey and completed the interview. 16.2\% of households contacted refused to be interviewed. $35.3 \%$ of households contacted were ineligible for the interview. 


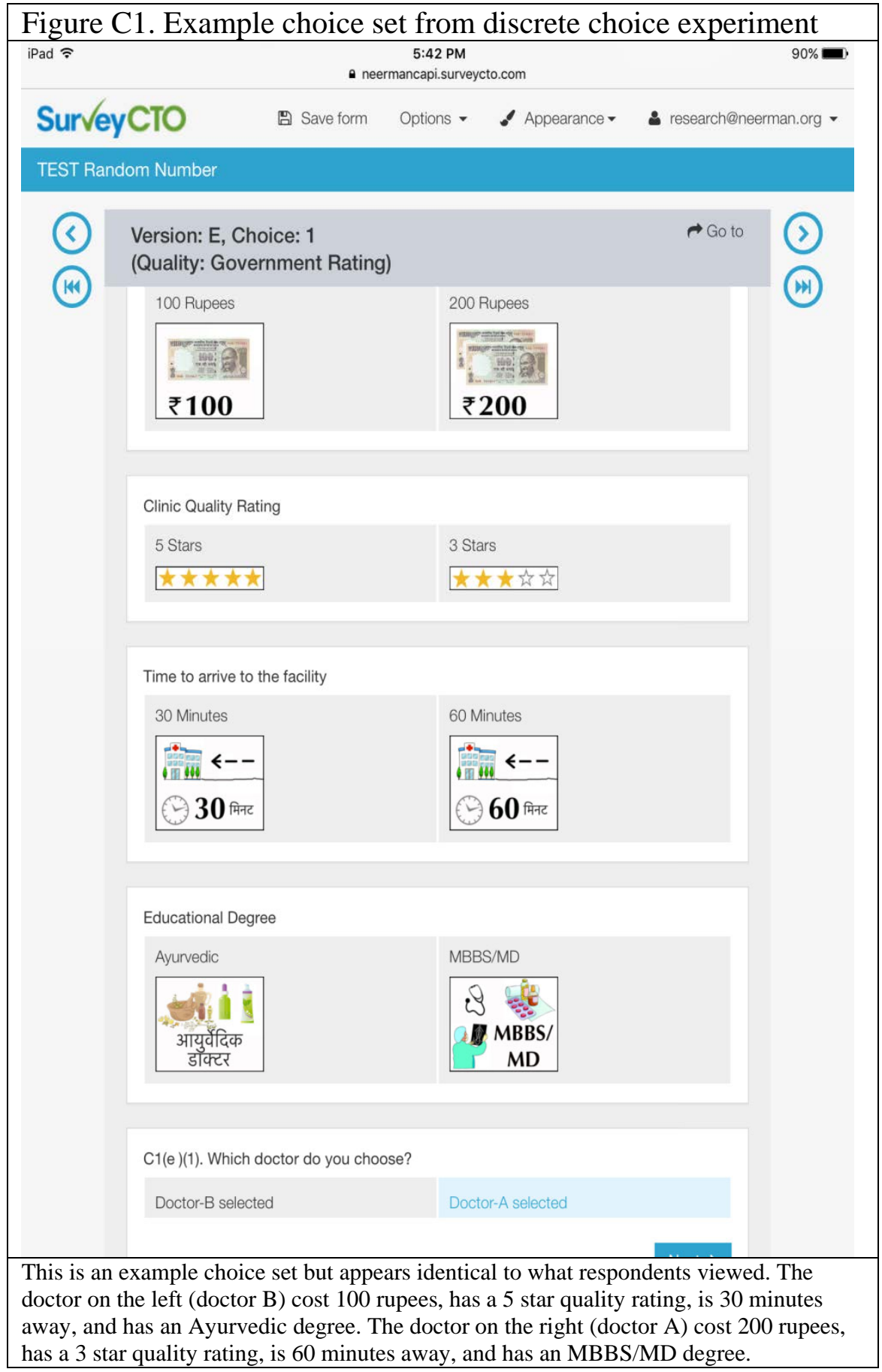


Table C1. Regression results for willingness to pay estimates

\begin{tabular}{|c|c|}
\hline VARIABLES & Pr(doctor chosen) \\
\hline Free (binary) & $\begin{array}{c}-0.213^{* * *} \\
(0.0324)\end{array}$ \\
\hline Price (1 rupee increase) & $\begin{array}{c}-0.000439 * * * \\
(0.000149)\end{array}$ \\
\hline Time (1 minute increase) & $\begin{array}{c}-0.00195 * * * \\
(0.000514)\end{array}$ \\
\hline \multicolumn{2}{|c|}{ Quality (reference = 1-star) } \\
\hline 3-stars & $\begin{array}{c}0.339 * * * \\
(0.0237)\end{array}$ \\
\hline 5-stars & $\begin{array}{c}0.643 * * * \\
(0.0214)\end{array}$ \\
\hline \multicolumn{2}{|c|}{ Degree (reference $=$ no degree) } \\
\hline Ayurvedic & $\begin{array}{c}0.494 * * * \\
(0.0242)\end{array}$ \\
\hline Homeopathic & $\begin{array}{c}0.482 * * * \\
(0.0291)\end{array}$ \\
\hline MBBS/MD & $\begin{array}{c}0.792 * * * \\
(0.0312)\end{array}$ \\
\hline Constant & $\begin{array}{c}-0.395^{* * *} \\
(0.0305)\end{array}$ \\
\hline Observations & 8,032 \\
\hline R-squared & 0.288 \\
\hline
\end{tabular}

Robust standard errors in parentheses

*** $\mathrm{p}<0.01,{ }^{* *} \mathrm{p}<0.05, * \mathrm{p}<0.1$ 


\section{Instructions for DCE as seen by respondents}

\section{Introduction to DCE}

We are interested in how people make decisions about health care and we hope that you can help us with this issue. There is no "correct" response to any of our questions and we just ask that you respond with your opinion. We will ask you to imagine what you would do if your child becomes ill. We will describe two types of doctors, and you should choose which one you would be most likely to go to for care for your child. These doctors will have different characteristics we are interested in learning about. Your responses are very important and they will directly inform decision making about health care in India. Therefore, please imagine that you are really going to make the decisions we are asking you to and answer truthfully. The doctors are different from each other in terms of the following four characteristics. Enumerator: demonstrate by hand signals that you are comparing two doctors

\section{Doctor Fees/Price}

The doctors will be charging different amount of fees for their service. Please assume that this amount is just for the doctor fees and any other charges for lab test, medicines etc. are the same for all doctors. There are four amounts of fees - Rs. 0 (Free service), Rs. 100, Rs. 200 and Rs. 300.

Doctor Fees: 0 Rupees (Show a photo)

Doctor Fees: 100 Rupees (Show a photo)

Doctor Fees: 200 Rupees (Show a photo)

Doctor Fees: 300 Rupees (Show a photo)

\section{Quality rating by Patient or Government (Randomly select either Patient or Government rating)}

\section{Patient Quality Rating For The Clinic}

Previous 50 patients have provided a quality rating based on their experience with these doctors, which is reflected using a star system from 1 to 5 stars; 5 stars represents excellent quality and 1 star represents very poor quality. Three stars looks this: and means the doctor is not "very poor quality" or "excellent quality" but somewhere in the middle.

Please remember that some of the previous patients may have rated the doctor five star and some even one start but we are showing you an average rating.

\section{Government Quality Rating For The Clinic}

Assume that the State Health Department visited all of the health facilities in your area and provided a single quality rating based on the quality of the doctor (e.g., prescribe the correct treatment, appropriate diagnosis, run all the correct tests, properly disinfect equipment, etc.). The quality rating is reflected using a star system. 5 stars ( ) represents perfect quality and 1 star ( ) represents very poor quality. Three stars looks this:

and means the doctor is not "very poor quality" or "perfect quality” but somewhere in the middle.

Rating: 5 Stars (Show a photo) 
Rating: 3 Stars (Show a photo)

Rating: 1 Star (Show a photo)

\section{Distance/time to arrive to facility}

We will ask about doctors that are at different distances from your home. Please assume that you will use same mode of transportation to visit each doctor.

For example, if we indicate that a doctor is 30 minutes away and you prefer to use the bus to arrive at a doctor's office, assume this means 30 minutes on bus. This time can be between 10 mins and 60 mins.

Time: 10 minutes (Show a photo)

Time: 20 minutes (Show a photo)

Time: 30 minutes (Show a photo)

Time: 60 minutes (Show a photo)

\section{Qualifications of the Doctor}

We will ask you about doctors that have different degree as follows,

1) Allopathy (English medicine) degree (e.g. MBBS or MD degree)

2) Homeopathy degree (e.g. BHMS, MD, Homeopath)

3) Ayurvedic degree (e.g. BAMS and MD, Ayurved)

4) Traditional healers without any formal medical degree

Degree: MBBS/ MD (Show a photo)

Degree: Homeopathic (BHMS) (Show a photo)

Degree: Ayurvedic (BAMS) (Show a photo)

Degree: No Degree (Show a photo)

\section{Diarrhea Vignette}

I will ask you to choose between two different doctors based on the characteristics we use to describe them.

Assume that all other characteristics between doctors are the same. For example, assume that the amount of the people in the waiting area, the number of seats, etc., is the same for all providers. Please choose which of the two doctors you would be most likely to visit. Even if you would prefer no doctor at all over the options given, please select which of the two doctors you would most prefer. After you make your choice, we will ask whether you would prefer to visit the chosen doctor or to not visit any doctor at all. It is very important that you think about what you would actually do in a real situation. If you need me to repeat the information about one or both of the doctors, please let me know. Feel free to ask questions.

Imagine that "child name" has been having diarrhea for the last 2 days. Each of these days he/she had 6 watery stools, fevers and he/she is now very weak and not eating or drinking very well. Now imagine that you have to choose between two different doctors from whom to seek care for your child. Let's try a practice round. It is important that you take this exercise seriously and choose the doctor that you expect you would actually choose in real life if your child had diarrhea. 